\title{
An Analytical Study of Partially Strengthened Single End-Bearing Granular Pile Near the Top and Bottom
}

https://doi.org/10.2478/sgem-2021-0010

received November 5, 2020; accepted April 22, 2021.

\begin{abstract}
Stone columns (or granular piles, GPs) are progressively being utilized for ground improvement, mostly for pliant edifice such as road mounds, oil depot, and so forth. The present analysis is done by introducing strengthening at both the ends of GP, i.e., bottom and top end so that the bulging problem will be solved and the beneficiary effect of the bearing stratum can be utilized by the bottom strengthening feature. Analysis of a single partially strengthened, at both top and bottom, end-bearing GP is presented in this article in terms of displacement affecting component for the top (DACT) of GP, percentage load transferred to the base (PLTB) of strengthened GP, and normalized shear stress (NSS). The PLTB of the strengthened GP was found to increase considerably. The NSS was found to reduce at the top end of GP and is found to be redistributed along the length of GP.
\end{abstract}

Keywords: granular pile; DACT of GP; NSS; PLTB of GP; reinforced stone columns; end-bearing GP.

\section{Introduction}

The adequate infrastructure of buildings, roads, tunnels, bridges, and other civil engineering works is a must for any country's progress. Consequently, construction is now done on places with enormously poor ground situations like soft clays, which cover a vast area in India. The rigorousness of the granular pile (GP) stops the horizontal enfolding of stones, hence aiding faster and cost-effective

*Corresponding author: Ashish Solanki, Department of Civil Engineering, Rajasthan Technical University, Kota, E-mail: asolanki. phd19@rtu.ac.in

Vaibhaw Garg, Jitendra Kumar Sharma, Department of Civil

Engineering, Rajasthan Technical University, Kota installation. The strengthening of the conventional GP may be achieved by (stiffened deep cement mixing) SDCM, use of geosynthetics, etc., which ultimately improves the performance of GP, owing to better mechanical properties of strengthening material used. For resolving the problem, the elastic continuum approach is applied. As the top and bottom portions are strengthened, a new matrix is created to introduce strengthening parameters for the top and bottom of GP. The parameter relative stiffness of bearing stratum, i.e., $\left(\mathrm{E}_{\mathrm{bs}} / \mathrm{E}_{\mathrm{ss}}\right)$, is defined for partially strengthened end-bearing GP, where " $\mathrm{E}_{\mathrm{bs}}$ " and " $\mathrm{E}_{\mathrm{ss}}$," are, respectively, the deformation modulus of bearing stratum and surrounding soft soil. The basic mirror image method is used to obtain the solution.

This study emphasizes the single end-bearing GP with its top and bottom portions strengthened, leaving some intermediate portion as unstrengthened for economic considerations. In past research, the effect of strengthening at the top was studied for getting rid of the bulging problem, as reported earlier. Now in this study, the bottom portion of end-bearing GP is also strengthened to take advantage of the bearing stratum, and as a result, it has been found to improve the performance of GP.

The analysis is based on the following assumptions:

i. It is assumed that the stress-strain relationship is of linear nature.

ii. To have a uniform distribution of load across the base of the granular pile and proper contact of the GP base with the base stratum, the base of the GP is considered as smooth by Madhav et al. [1] across which the load is uniformly distributed.

iii. A linear performance is presumed to be applicable for soil, and simultaneously, it is supposed to be homogeneous and isotropic.

iv. It is assumed that there will be no slip or yield state at the granular pile-soil interface, owing to its rough nature. 


\section{Literature Review}

In earlier investigational and mathematical methodologies for studying the performance of GPs, several investigators have contributed. Meanwhile, in 1969 with the pioneer study of Mattes and Poulos [2] in the area of GPs, as a ground improvement technique, several researchers have worked in this area, providing innovative elevations to this area. Priebe [3] proposed the reduced stress method for quantifying a decrease in settlement of soft ground reinforced with columns made up of stones. Ambily and Gandhi [4] performed drained elasto-plastic examination using Mohr-Coulomb's principle for soft clay, stones, and sand. Numerical results from the FEM link well with the experimental results. Black et al. [5] examined the performance of columns made up of stones in a weak deposit with the effect of reinforcing stone columns by jacketing with a tubular wire mesh by connecting reinforcement with a metal rod and a concrete plug. It was found that the load settlement response was increased significantly by adopting various methods of reinforcing. Madhav et al. [6] studied the interactions among a GP and raft positioned on top using the continuum approach. It was found that the percentage load carried by the granular pile (GP) increases with the increase of its relative stiffness and decreases with the increase of the relative size of the raft. Wang [7] solved the differential equations of the foundation reinforced by stone columns using a semi-analytical method, and the results obtained were comparable with the existing analytical solutions. Najjar et al. [8] assessed the degree of improvement in the mechanical properties of soft clays in practical applications, including the use of sand drains or sand columns in clayey soils, by changing the parameter of the diameter of the sand column. Test results indicated that sand columns improved the un-drained strength significantly, even for area replacement ratios less than $18 \%$. Black et al. [9] did physical model tests to recognize the settlement characteristics, mainly in relation to smallgroup configurations. For the control of settlements, it was found that an optimum area replacement ratio of $30 \%-40 \%$ exists. Yoo [10] presented a three-dimensional finite-element model to bring out a parametric study on several leading aspects such as the consistency of soft ground, the geo-synthetic encasement length and stiffness, embankment fill height, and area replacement ratio. An overall reduction in settlement was observed due to additional confinement provided by the geo-synthetic encasement. Shahu and Reddy [11] studied small scale model tests of floating stone columns group and the parameters affecting the group response are recognized as ratio of area, length of column, column's deformation modulus etc. Shahu and Reddy [12] gave design charts for assessing long-term drained settlement of floating stone column group foundations which were based on threedimensional, elasto-plastic, finite elementanalyses. Etezad et al. [13] presented an analytical model for determination of the bearing capacity of soft soil strengthened with stone columns under rigid raft foundation and subjected to a general shear-failure mechanism. Hosseinpour et al. [14] experimentally obtained the soil curving developed during post-construction due to a reduction in apparent stiffness of soft clay from virtual un-drained to drained stiffness. Hong et al. [15] examined the impacts of geotextile encased granular columns used in areas having soft soils through model tests. Experimental results show that encasement improves the bearing capacity of all modeled sand columns, even when encasement rupture occurs. Garg and Sharma [16] analytically carried out the settlement analysis of a single and group of two partially floating granular piles. The settlement at the top of the GP was found to decrease with the introduction of stiffening at the top. Madhav et al. [17] presented the analytical solution for studying the settlement analysis of a group of two partially stiffened end bearing GPs. They revealed the advantageous effect of partial stiffening, in increasing the load sharing characteristic of the base of the GP. Nav et al. [21] concluded that when columns are used in combination with geosynthetics, the soil settlement reduces. Szypcio [22] presented the problem of plastic yielding at the head of a single column head and soil in the surroundings. The settlement influence factor for an end-bearing granular pile decreases with an increase in the bearing stratum's relative stiffness, as concluded by Sharma and Gupta [23].

\section{Description of Problem}

Fig. 1 (a), (b), and (c) depict the basic plot of the problem, where a single end bearing GP having its top and bottom both portions strengthened is presented. The length of end-bearing GP is taken as " $\mathrm{L}_{\mathrm{g}}$ " while its diameter as " $\mathrm{D}_{\mathrm{g}}$ " $=(2 \mathrm{a})$. GP is assumed to be subjected to an axial load "F". " $F_{b}$ " is considered the load transferred to the base of the strengthened GP. Fig. 1 (a) shows that the top portion of single end-bearing GP is strengthened upto some definite length " $L_{t}$ " and similarly bottom portion of GP is also strengthened for a length " $L_{b}$ ". A parameter " $\eta_{t}$ " $\left(=\mathrm{L}_{\mathrm{t}} / \mathrm{L}_{\mathrm{g}}\right)$ is chosen to show the strengthening phenomenon at the top portion of the GP. At the same time, " $\eta_{b}$ " $\left(=L_{b} /\right.$ $\mathrm{L}_{\mathrm{g}}$ ) denotes the strengthening effect taken at the bottom 
end of the GP, leaving some portion at the middle to be unstrengthened. " $E_{t s p}$," " $E_{b s p}$," " $E_{\text {musp }}$ " " $E_{s s}$ " and " $E_{b s}$ " are, respectively, the modulus of deformation, of the granular pile in the top strengthened portion, bottom strengthened portion, middle un-strengthened portion, the surrounding soft soil, and the bearing stratum. The Poisson's ratio of surrounding soft soil and bearing stratum are, respectively, represented by " $v_{s s}$ " and " $v_{b s}$ ". The relative stiffness of GP and bearing stratum are, respectively, defined $-\mathrm{K}_{\mathrm{p}}=\mathrm{E}_{\text {musp }} /$ $\mathrm{E}_{\mathrm{ss}}$, i.e., the ratio of modulus of deformation of the middle portion of the GP to that of the surrounding soft soil and $\mathrm{K}_{\mathrm{bs}}=\mathrm{E}_{\mathrm{bs}} / \mathrm{E}_{\mathrm{ss}}$, i.e., the ratio of modulus of deformation of bearing stratum to that of the surrounding soft soil. For taking the degree of strengthening into account for the top and bottom portion of the GP, respectively, the parameters " $\chi_{t}$ " and " $\chi_{b}$ " were introduced. " $\chi_{t}$ " is the factor by which the " $K_{p}$," of the unstrengthened portion of GP, is multiplied to get the " $\mathrm{K}_{\mathrm{p}}$ " of the top strengthened portion of the GP and similarly, " $\chi_{b}$ " is the factor by which the " $\mathrm{K}$ ", of the unstrengthened portion of GP is multiplied to get the " $\mathrm{K}_{\mathrm{p}}$," of the bottom, strengthened portion of the GP. The value of $\chi_{t}$ and $\chi_{b}$ both is $\geq 1$, being unity for the unstrengthened condition of GP and greater than unity for the strengthened condition of GP. The relative length of GP is defined as $\mathrm{L}_{\mathrm{g}} / \mathrm{D}_{\mathrm{g}}$, i.e., ratio of length and diameter of the GP. $z_{\mathrm{g}}$ is taken as the depth of an element from the top of the GP, and $\mathrm{z}_{\mathrm{g}}{ }_{\mathrm{g}}=\mathrm{Z}_{\mathrm{g}} / \mathrm{L}_{\mathrm{g}}$ is defined as the normalized depth.

\section{Method Adopted for Analysis}

The basic mirror image technique, as shown in Fig. 2, is applied to obtain the solution with the simultaneous imposition of elastic continuum approach. Following section deals with the method used for analysis.

\subsection{Soil Displacements}

For carrying out the analysis, the basic discretization and the integration scheme suggested by Mindlin [18-19] is used. So, the partially strengthened GP is discretized into "n" cylindrical elements. GP is assumed to be acted upon by shear stresses, $\tau$, while $\tau_{\mathrm{E}}^{\star}=\tau\left(\pi \mathrm{D}_{\mathrm{g}} \mathrm{L}_{\mathrm{g}}\right) / \mathrm{F}$ is the NSS. It was considered that a uniform pressure " $\mathrm{p}_{\mathrm{b}}$ " is developed across the base of the GP. For the sake of analysis, nodes were considered at the periphery (at the center of each discretized element) and center of the base of GP. The soil displacements of the nodes were evaluated based on the influence of the elemental shear stresses. Thus, soil

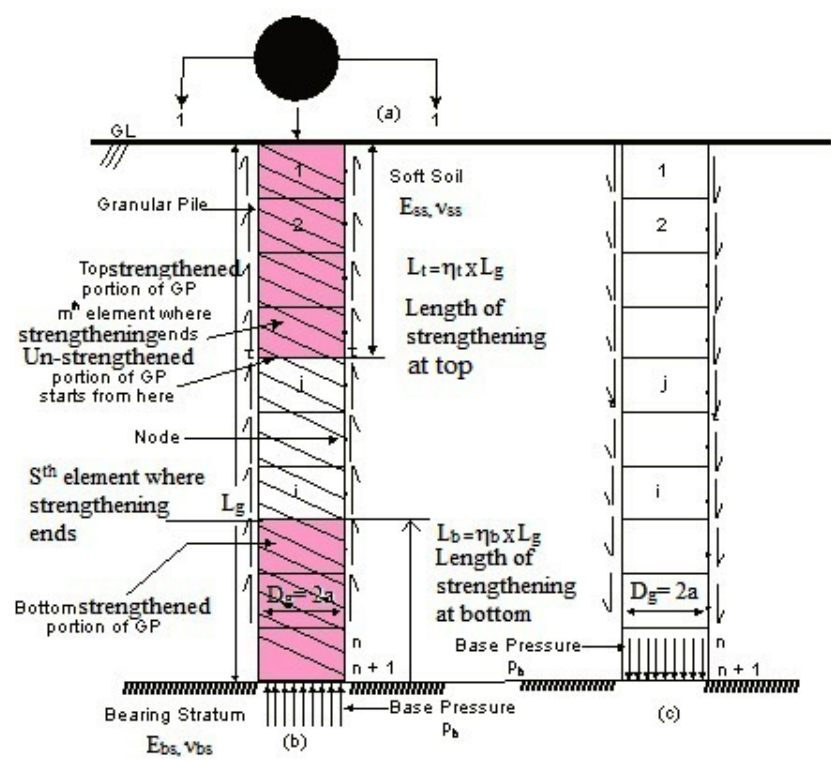

Figure 1: (a) Plan of strengthened end bearing GP (b) Sectional elevation at 1-1 of a single strengthened end bearing GP, subjected to load F, revealing strengthening effect. (c) Problem description sketch, development of interfacial shear stresses on soil due to a single strengthened end-bearing GP.

displacement equations for a GP which is end-bearing, are given by Mattes and Poulos [2] as described by Eq. (1).

$$
\left\{\rho^{s d}\right\}=\left\{\frac{\mathrm{S}^{\mathrm{sd}}}{\mathrm{Dg}_{\mathrm{g}}}\right\}=\left[\left[\mathrm{IFC}^{\mathrm{sd}}\right]-\psi\left[\mathrm{IFC} \mathrm{Cdim}^{\mathrm{sdi}}\right]\right]\left\{\frac{\tau}{\mathrm{E}_{\mathrm{ss}}}\right\}
$$

where $\left\{S^{\mathrm{sd}}\right\}$ and $\left\{\rho^{\text {sd }}\right\}$ in Eq. (1) are, respectively, the soil displacement and normalized soil displacement vectors each of size "n," while $\left\{\tau / \mathrm{E}_{\mathrm{ss}}\right\}$ is a column vector of size $(n+1)$. In order to account for the effect of bearing stratum, the mirror image approximation Poulos and Mattes [20] is applied. For considering the effect of the mirror image elements, a non-dimensional parameter, $\psi$, is chosen, which takes into account the compressibility of the base and its value lying between 0 and 1 . The exact value of $\psi$ is 0 for floating GP and 1 for end-bearing GP. The impact of the elements of the mirror image is taken as, $\psi$, times the influence of shear stresses on the real elements in the reverse direction. In Eq. (1), [IFC $\left.{ }^{\text {sd }}\right]$ denotes the soil displacement influence coefficients, and [IFC $\left.{ }^{\text {sdim }}\right]$ represents the soil displacement influence coefficients due to image elements, both are square matrices each of size " $n$ ". 


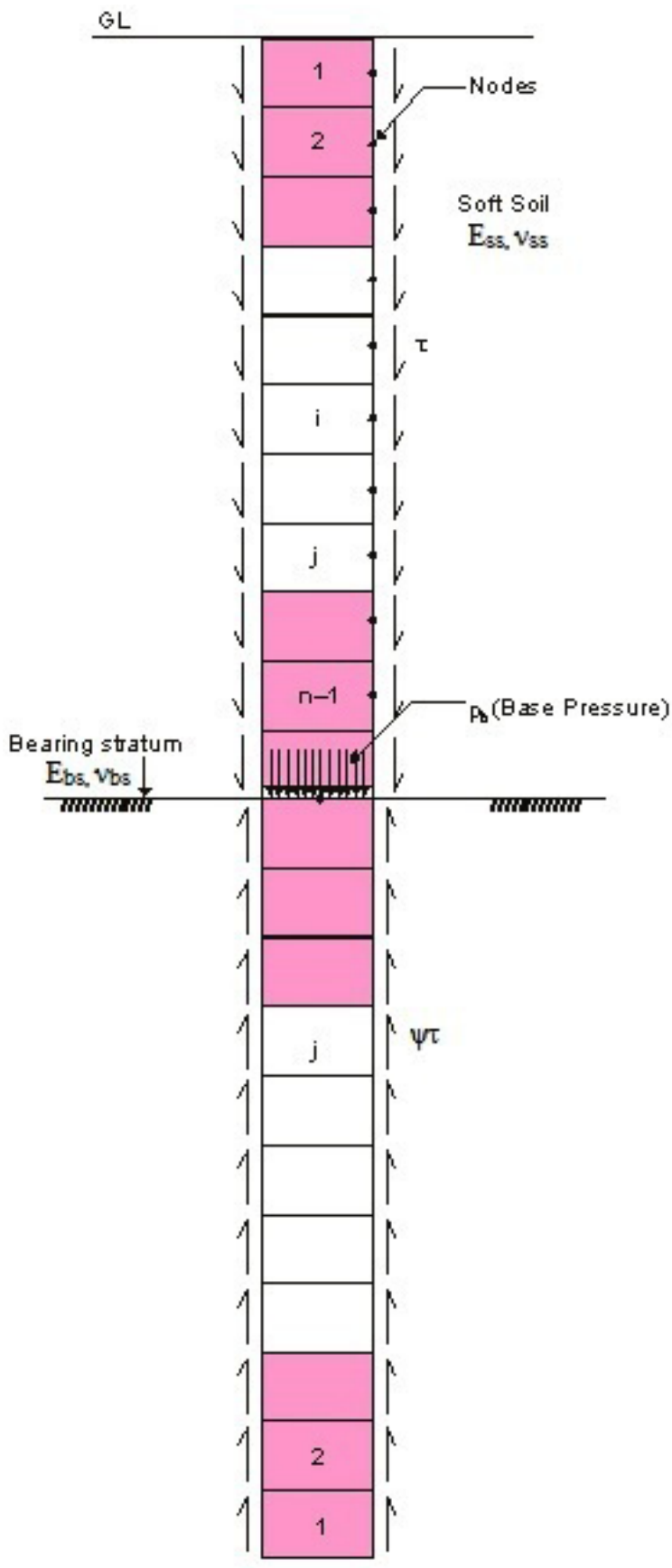

Figure 2: Basic mirror image methodology for GP.

\subsection{Granular Pile Displacements}

Following analysis is carried out to obtain the GP displacements for end bearing GP resting on a relatively stiff bearing stratum. Boussinesqs' equation is used to obtain the displacement of a rigid circular disc on a semi-infinite mass. So, by using Boussinesqs' equation, displacement of the base of a GP resting on a bearing stratum of some finite compressibility is approximated by

$$
\rho_{\mathrm{b}}^{\mathrm{p}}=\frac{\mathrm{s}_{\mathrm{b}}^{\mathrm{p}}}{\mathrm{D}_{\mathrm{g}}}=\frac{\mathrm{p}_{\mathrm{b}}\left(1-v_{\mathrm{bs}}^{2}\right) \pi / 4}{\mathrm{E}_{\mathrm{bs}}}
$$

In order to express the base pressure in terms of shear stresses, as given by Eq.(3), equilibrium equation is used as under,

$$
\mathrm{p}_{\mathrm{b}}=\frac{\mathrm{F}}{\pi \mathrm{D}_{\mathrm{g}}^{2} / 4}-\frac{4\left(\mathrm{Lg} / \mathrm{D}_{\mathrm{g}}\right)}{\mathrm{n}} \sum_{\mathrm{j}=1}^{\mathrm{j}=\mathrm{n}} \tau_{\mathrm{j}}
$$

Hence, using the applied load and mobilized shear stresses, the normalized settlement of the base (using Eq. - s (2) and (3)) can be expressed as

$$
\rho_{\mathrm{b}}=\left[\frac{\mathrm{F}}{\mathrm{E}_{\mathrm{ss}} \pi \mathrm{D}_{\mathrm{g}}^{2} / 4}-\frac{4\left(\mathrm{Lg} / \mathrm{D}_{\mathrm{g}}\right)}{\mathrm{n}} \sum_{\mathrm{j}=1}^{\mathrm{j}=\mathrm{n}} \frac{\tau_{\mathrm{j}}}{\mathrm{E}_{\mathrm{ss}}}\right] \times \frac{\pi\left(1-v_{\mathrm{bs}}^{2}\right)}{4\left(\mathrm{E}_{\mathrm{bs}} / \mathrm{E}_{\mathrm{ss}}\right)}
$$

To evaluate the displacement of any $\mathrm{i}^{\text {th }}$ element lying in the bottom strengthened portion of the GP, where $s \leq i \leq n$, it is assumed that bottom strengthening is done from the bottom $\mathrm{n}^{\text {th }}$ element to the $\mathrm{S}^{\text {th }}$ element as shown in Fig. 1 (b). The displacement of the base is added with the displacement of the element due to the axial stress acting on it as given by

$$
\rho_{\mathrm{i}}^{\mathrm{p}}=\rho_{\mathrm{b}}^{\mathrm{p}}+\sum_{\mathrm{j}=\mathrm{n}}^{\mathrm{j}=\mathrm{i}-1} \frac{\sigma_{\mathrm{j}}}{\mathrm{E}_{\mathrm{bsp}}}\left(\Delta \mathrm{z} / \mathrm{D}_{\mathrm{g}}\right)+\frac{\sigma_{\mathrm{i}}}{\mathrm{E}_{\mathrm{bsp}}}\left(\Delta \mathrm{z} / 2 \mathrm{D}_{\mathrm{g}}\right)
$$

where $\sigma_{j} / E_{b s p}$, is axial strain of the $j^{\text {th }}$ element, $\sigma_{i} / E_{b s p}$, is axial strain of the $\mathrm{i}^{\text {th }}$ element, and $\Delta \mathrm{z}$ is the length of element.

In the above analysis, in order to maintain the compatibility of displacements at the junction of strengthened and unstrengthened bottom portion of GP, due consideration is observed. As shown in Fig. 1 (b), the bottom strengthening is carried out till the end of the $S^{\text {th }}$ element from the bottom of the GP. The displacement at the top of the $\mathrm{S}^{\text {th }}$ element or bottom of the $(\mathrm{S}+1)^{\text {th }}$ element, i.e., interface of bottom strengthened and an unstrengthened portion of GP, is as given below:

$$
\rho_{\text {bottom interface }}^{\mathrm{p}}=\rho_{\mathrm{b}}^{\mathrm{p}}+\sum_{\mathrm{j}=\mathrm{n}}^{\mathrm{j}=\mathrm{S}} \frac{\sigma_{\mathrm{j}}}{\mathrm{E}_{\mathrm{bsp}}}\left(\Delta \mathrm{z} / \mathrm{D}_{\mathrm{g}}\right)
$$


To satisfy the compatibility at the interface between the bottom strengthened and an unstrengthened portion of GP, the displacement of the bottom end of the $(\mathrm{S}+1)$ th element of the unstrengthened portion is taken as the displacement of top of the $S^{\text {th }}$ element of strengthened portion of GP. Hence, the displacement of $(\mathrm{S}+1)^{\text {th }}$ element is evaluated as

$$
\rho_{\mathrm{i}=S+1}^{\mathrm{p}}=\rho_{\mathrm{b}}^{\mathrm{p}}+\sum_{\mathrm{j}=\mathrm{n}}^{\mathrm{j}} \frac{\sigma_{\mathrm{j}}}{\mathrm{E}_{\mathrm{bsp}}}\left(\Delta \mathrm{z} / \mathrm{D}_{\mathrm{g}}\right)+\frac{\sigma_{\mathrm{i}}}{\mathrm{E}_{\mathrm{musp}}}\left(\Delta \mathrm{z} / 2 \mathrm{D}_{\mathrm{g}}\right)
$$

The displacement of any $i^{\text {th }}$ element lying in the middle unstrengthened portion of the GP, i.e., $\mathrm{m} \leq \mathrm{i} \leq \mathrm{S}$, is given by

$$
\begin{array}{r}
\rho_{\mathrm{i} \text { middle }}^{\mathrm{p}}=\rho_{\mathrm{b}}^{\mathrm{p}}+\sum_{\mathrm{j}=\mathrm{n}}^{\mathrm{j}=\mathrm{S}} \frac{\sigma_{\mathrm{j}}}{\mathrm{E}_{\mathrm{bsp}}}\left(\Delta \mathrm{z} / \mathrm{D}_{\mathrm{g}}\right)+ \\
+\sum_{\mathrm{j}=\mathrm{S}+1}^{\mathrm{j}=\mathrm{i}-1} \frac{\sigma_{\mathrm{j}}}{\mathrm{E}_{\text {musp }}}\left(\frac{\Delta \mathrm{z}}{\mathrm{D}_{\mathrm{g}}}\right)+\frac{\sigma_{\mathrm{i}}}{\mathrm{E}_{\text {musp }}}\left(\Delta \mathrm{z} / 2 \mathrm{D}_{\mathrm{g}}\right)
\end{array}
$$

In order to satisfy the compatibility at top interface between strengthened and unstrengthened portion of GP, the displacement of the bottom end of the $\mathrm{m}^{\text {th }}$ element of strengthened portion is taken as the displacement of the top of the $(m+1)^{\text {th }}$ element of unstrengthened portion of GP. Hence the displacement of $\mathrm{m}^{\text {th }}$ element is evaluated as

$$
\rho_{\text {top interface, } i=m}^{\mathrm{p}=\mathrm{m}}=\rho_{\mathrm{b}}^{\mathrm{p}}+\sum_{\mathrm{j}=\mathrm{n}}^{\mathrm{j}=\mathrm{n}} \frac{\sigma_{\mathrm{j}}}{\mathrm{E}_{\mathrm{bsp}}}\left(\Delta \mathrm{z} / \mathrm{D}_{\mathrm{g}}\right)+\sum_{\mathrm{j}=\mathrm{S}+1}^{\mathrm{j}=\mathrm{m}} \frac{\sigma_{\mathrm{j}}}{\mathrm{E}_{\mathrm{musp}}}\left(\Delta \mathrm{z} / \mathrm{D}_{\mathrm{g}}\right)
$$

In order to find out the displacement of any $\mathrm{i}^{\text {th }}$ element lying in the top strengthened portion of the GP, i.e., $1 \leq i \leq m$, the following equation is utilized.

$$
\begin{aligned}
\rho_{1 \leq i \leq \mathrm{m}}^{\mathrm{p}}= & \rho_{\mathrm{b}}^{\mathrm{p}}+\sum_{\mathrm{j}=\mathrm{n}}^{\mathrm{j}=\mathrm{S}} \frac{\sigma_{\mathrm{j}}}{\mathrm{E}_{\mathrm{bsp}}}\left(\Delta \mathrm{z} / \mathrm{D}_{\mathrm{g}}\right)+\sum_{\mathrm{j}=\mathrm{S}+1}^{\mathrm{j}=\mathrm{m}} \frac{\sigma_{\mathrm{j}}}{\mathrm{E}_{\mathrm{musp}}}\left(\Delta \mathrm{z} / \mathrm{D}_{\mathrm{g}}\right)+ \\
& +\sum_{\mathrm{j}=\mathrm{m}}^{\mathrm{j}=\mathrm{i}-1} \frac{\sigma_{\mathrm{j}}}{\mathrm{E}_{\mathrm{tsp}}}\left(\Delta \mathrm{z} / \mathrm{D}_{\mathrm{g}}\right)+\frac{\sigma_{\mathrm{i}}}{\mathrm{E}_{\mathrm{tsp}}}\left(\Delta \mathrm{z} / 2 \mathrm{D}_{\mathrm{g}}\right)
\end{aligned}
$$

Using the matrix form, the above set of displacement equations is expressed as

$$
\left\{\rho^{p}\right\}=\rho_{b}\{1\}+\left[M A T_{1}\right]\left\{\frac{\sigma}{E_{S S}}\right\}
$$

In Eq. (11), $\left[\mathrm{MAT}_{1}\right]$ is an upper triangular matrix of size $(n \times n)$ obtained by incorporating the strengthening parameters for top and bottom of the granular pile in Eq. (5) and is given by Eq. (12)

$$
\left[\mathrm{MAT}_{1}\right]=\frac{\left(\frac{\mathrm{Lg}}{\mathrm{Dg}}\right)}{\mathrm{nK} \mathrm{p}_{\mathrm{p}}}\left[\begin{array}{cccccccccc}
\frac{0.5}{\chi_{t}} & \frac{1}{\chi_{t}} & \frac{1}{\chi_{t}} & 1 & - & - & \frac{1}{\chi_{b}} & \frac{1}{\chi_{b}} & \frac{1}{\chi_{b}} \\
0 & \frac{0.5}{\chi_{t}} & \frac{1}{\chi_{t}} & 1 & - & - & \frac{1}{\chi_{b}} & \frac{1}{\chi_{b}} & \frac{1}{\chi_{b}} \\
0 & 0 & \frac{0.5}{\chi_{t}} & 1 & - & - & \frac{1}{\chi_{b}} & \frac{1}{\chi_{b}} & \frac{1}{\chi_{b}} \\
0 & 0 & 0 & 0.5 & - & - & \frac{1}{\chi_{b}} & \frac{1}{\chi_{b}} & \frac{1}{\chi_{b}} \\
. & . & . & . & . & . & \frac{1}{\chi_{b}} & \frac{1}{\chi_{b}} & \frac{1}{\chi_{b}} \\
0 & 0 & 0 & 0 & 0.5 & 1 & \frac{1}{\chi_{b}} \\
0 & 0 & 0 & 0 & 0 & 0.5 & \frac{1}{\chi_{b}} & \frac{1}{\chi_{b}} & \frac{1}{\chi_{b}} \\
. & . & . & . & . & . & . & . & \frac{0.5}{\chi_{b}}
\end{array}\right]
$$

Further using Eq. (4) for replacing the base displacement, Eq. (11) can be rewritten as

$$
\left\{\rho^{\mathrm{p}}\right\}=\frac{\mathrm{F}\left(1-v_{\mathrm{b}}^{2}\right)}{\left(\mathrm{E}_{\mathrm{bs}} / \mathrm{E}_{\mathrm{ss}}\right) \mathrm{D}_{\mathrm{g}}^{2} \mathrm{E}_{\mathrm{ss}}}\{1\}-\frac{\pi\left(\mathrm{Lg}_{\mathrm{g}} / \mathrm{D}_{\mathrm{g}}\right)\left(1-v_{\mathrm{b}}^{2}\right)}{\mathrm{n}\left(\mathrm{E}_{\mathrm{bs}} / \mathrm{E}_{\mathrm{ss}}\right)}[1]\left\{\frac{\tau}{\mathrm{E}_{\mathrm{ss}}}\right\}+\left[\mathrm{MAT}_{1}\right]\left\{\frac{\sigma}{\mathrm{E}_{\mathrm{ss}}}\right\}
$$

Here, $\{1\}$ and [1] are, respectively, unit column vector and unit square matrix each of size "n." Based on equilibrium relationship, the shear stresses in the shaft and axial stresses of elements are interconnected by the following equation:

$$
\sigma_{\mathrm{i}}=\frac{\mathrm{F}}{\left(\pi \mathrm{D}_{\mathrm{g}}^{2} / 4\right)}-\sum_{\mathrm{j}=1}^{\mathrm{j}=\mathrm{i}-1} \frac{4 \tau_{\mathrm{j}} \mathrm{Lg}}{\mathrm{nDg}}-\frac{2 \tau_{\mathrm{i}} \mathrm{Lg}}{\mathrm{nDg}}
$$

Using matrix form, the above equation may be written for elements $i=1$ to " $n$ " as

$$
\left\{\frac{\sigma}{\mathrm{E}_{\mathrm{sS}}}\right\}=\frac{\mathrm{F}}{\left(\pi \mathrm{D}_{\mathrm{g}}^{2} / 4\right) \mathrm{E}_{\mathrm{ss}}}-\frac{4\left(\mathrm{Lg}_{\mathrm{g}} / \mathrm{D}_{\mathrm{g}}\right)}{\mathrm{n}}\left[\mathrm{MAT}_{2}\right]\left\{\frac{\tau}{\mathrm{E}_{\mathrm{ss}}}\right\}
$$

where $\left[\mathrm{MAT}_{2}\right]$ is a lower triangular matrix having the diagonal and off-diagonal terms as 0.5 and 1.0, respectively, and is of size "n."

The final form of displacement equations for elements $\mathrm{i}=1$ to " $\mathrm{n}$ " in terms of shaft shear stresses Eq. (15) is obtained in Eq. (16), using the relationship between axial stresses and shaft shear stresses:

$$
\left\{\rho^{p}\right\}=\{Y\}+[M A T]\left\{\frac{\tau}{E_{S S}}\right\}
$$


where

$$
\begin{gathered}
\{\mathrm{Y}\}=\frac{\mathrm{F}\left(1-v_{\mathrm{bs}}^{2}\right)}{\left(\mathrm{E}_{\mathrm{bs}} / \mathrm{E}_{\mathrm{ss}}\right) \mathrm{D}_{\mathrm{g}}^{2} \mathrm{E}_{\mathrm{ss}}}\{1\}+\frac{\mathrm{F}}{\left(\pi \mathrm{D}_{\mathrm{g}}^{2} / 4\right) \mathrm{E}_{\mathrm{ss}}}\left[\mathrm{MAT}_{1}\right]\{1\} \\
{[\mathrm{MAT}]=-\frac{4\left(\mathrm{Lg} / \mathrm{Dg}_{\mathrm{g}}\right)}{\mathrm{n}}\left[\mathrm{MAT}_{1}\right]\left[\mathrm{MAT}_{2}\right]-\frac{\pi\left(\mathrm{Lg}_{\mathrm{g}} / \mathrm{D}_{\mathrm{g}}\right)\left(1-v_{\mathrm{bs}}^{2}\right)}{\mathrm{n}\left(\mathrm{E}_{\mathrm{bs}} / \mathrm{E}_{\mathrm{ss}}\right)}[1]}
\end{gathered}
$$

\subsection{Soil and Strengthened GP Displacement Compatibility}

Solutions are obtained in terms of interface shear stresses and base pressure, after applying the compatibility of displacements of the GP and the soil as described below,

The interface shear stresses are evaluated for granular pile resting on stiff bearing stratum using Eq.-s (1) and (16) as

$$
\left\{\frac{\tau}{E_{S S}}\right\}=\left[\left[I F C^{s d}\right]-\psi\left[I F C^{s d i m}\right]-[M A T]\right]^{-1}\{Y\}
$$

The iterative technique (Poulos and Mattes [20]) is used, for estimating $\psi$. Eq. - s (18) and (3) are solved to evaluate the " $n$ " unknown shear stresses, $\tau$, and base pressure, $\mathrm{p}_{\mathrm{b}}$, by allocating some initial value to, $\psi$. After getting the solution for that initial allocated value of $\psi$, a more accurate value is evaluated for $\psi$, by considering the compatibility between displacements of soil and the bearing stratum at the pile tip. At the pile tip, the soil displacement is given by

$$
\rho_{\mathrm{b}}^{\mathrm{s}}=\frac{\mathrm{S}_{\mathrm{b}}^{\mathrm{s}}}{\mathrm{D}_{\mathrm{g}}}=\left\{\mathrm{IFC}_{\mathrm{j}}^{\mathrm{sd}}-\psi \mathrm{IFC}_{\mathrm{j}}^{\text {sdim }}\right\}\left\{\frac{\tau}{\mathrm{E}_{\mathrm{ss}}}\right\}=\frac{\left.\sum_{\mathrm{j}=1}^{\mathrm{j}=\mathrm{n}_{1}} \mathrm{IFC}_{\mathrm{j}}^{\text {sd }}-\psi \mathrm{IFC}_{\mathrm{j}}^{\text {sdim }}\right) \tau_{\mathrm{j}}}{\mathrm{E}_{\mathrm{ss}}}(19)
$$

Due to shear stresses on real and imaginary elements " $\mathrm{j}$," in the above equation, $I F C_{j}^{s l}$ and $I F C_{j}^{s \text { dim }}$ are the displacement influence coefficients for the tip, respectively. But due to symmetrical conditions, $I F C_{j}^{s}=I F C_{j}^{s \mathrm{dim}}$. Now the new values of the parameter $\psi$ are obtained by equating the soil displacement at the pile tip to the displacement of the base due to base stress, $p_{b}$, Eq. (2) as given by

$$
\psi=1-\frac{\pi\left(1-v_{\mathrm{bs}}^{2}\right) \mathrm{p}_{\mathrm{b}}}{4\left(\mathrm{E}_{\mathrm{bs}} / \mathrm{E}_{\mathrm{ss}}\right) \sum_{\mathrm{j}=1}^{\mathrm{j}=\mathrm{n}} \tau_{\mathrm{j}} \mathrm{IFC}}
$$

Table 1: Validation of results.

\begin{tabular}{lclll}
\hline $\begin{array}{l}\text { Variables } \\
\text { verified }\end{array}$ & $\mathrm{L}_{\mathrm{g}} / \mathrm{D}_{\mathrm{g}}$ & $\begin{array}{l}\mathrm{K}_{\mathrm{p}} \text { and } \\
\mathrm{E}_{\mathrm{bs}} / \mathrm{E}_{\mathrm{ss}}\end{array}$ & $\begin{array}{l}\text { Results of } \\
\text { Poulos and } \\
\text { Mattes [20] }\end{array}$ & $\begin{array}{l}\text { Present } \\
\text { analysis with } \\
\left(\mathrm{X}_{\mathrm{f}}=\mathrm{X}_{\mathrm{b}}=1\right)\end{array}$ \\
\hline $\begin{array}{l}\mathrm{DACT}\left(\mathrm{D}_{\mathrm{T}}\right) \\
\text { of GP }\end{array}$ & 25 & $\begin{array}{l}100 \text { and } \\
10\end{array}$ & 0.54 & 0.539 \\
& 25 & $\begin{array}{l}100 \text { and } \\
100\end{array}$ & 0.51 & 0.508 \\
& 25 & $\begin{array}{l}100 \text { and } \\
1000\end{array}$ & 0.49 & 0.489 \\
& 20 & $\begin{array}{l}100 \text { and } \\
100000\end{array}$ & 0.09 & 0.0899 \\
& & & \\
\hline
\end{tabular}

This process of iteration is repeated as just described again and again by solving Eq. (18) iteratively using the new value of $\psi$, and the process is repeated until the percentage difference between the new value of $\psi$ and last calculated value of $\psi$ becomes as low as $0.01 \%$, i.e., a very high-order convergence is achieved. The normalized top displacement of a single partially strengthened GP is obtained as

$$
\rho_{\text {top }}=\frac{S_{\text {top }}}{D_{g}}=\frac{F}{\frac{\pi}{4} E_{s s} D_{g}^{2}} D_{T}
$$

The top displacement of a single partially stiffened GP is obtained as

$$
S_{\text {top }}=\frac{F}{\frac{\pi}{4} E_{s s} D_{g}} D_{T}
$$

In above Eq. $-\mathrm{S}$ (21) and (22), $\mathrm{D}_{\mathrm{T}}$ is the displacement affecting component for the top (DACT) of GP.

The parameters that are found affecting the above displacement analysis are enlisted:

(i) Relative length, i.e., ratio of length and diameter of the GP, $\left(\mathrm{L}_{\mathrm{g}} / \mathrm{D}_{\mathrm{g}}\right)$,

(ii) The relative stiffness of $\mathrm{GP}, \mathrm{K}_{\mathrm{p}}=\left(\mathrm{E}_{\text {musp }} / \mathrm{E}_{\mathrm{ss}}\right)$,

(iii) In the case of the end bearing GP, the relative stiffness of bearing stratum, $\mathrm{K}_{\mathrm{bs}}=\mathrm{E}_{\mathrm{bs}} / \mathrm{E}_{\mathrm{ss}}$.

(iv) Poisson's ratios of the surrounding soft soil, $v_{\mathrm{ss}}$ and that of the base stratum, $v_{\mathrm{bs}}$.

(v) Percentage length of strengthening from the top (PLST) of GP, $\eta_{t}\left(=L_{t} / L_{g}\right)$.

(vi) Percentage length of strengthening from the bottom (PLSB) of GP, $\eta_{b}\left(=L_{b} / L_{g}\right)$. 


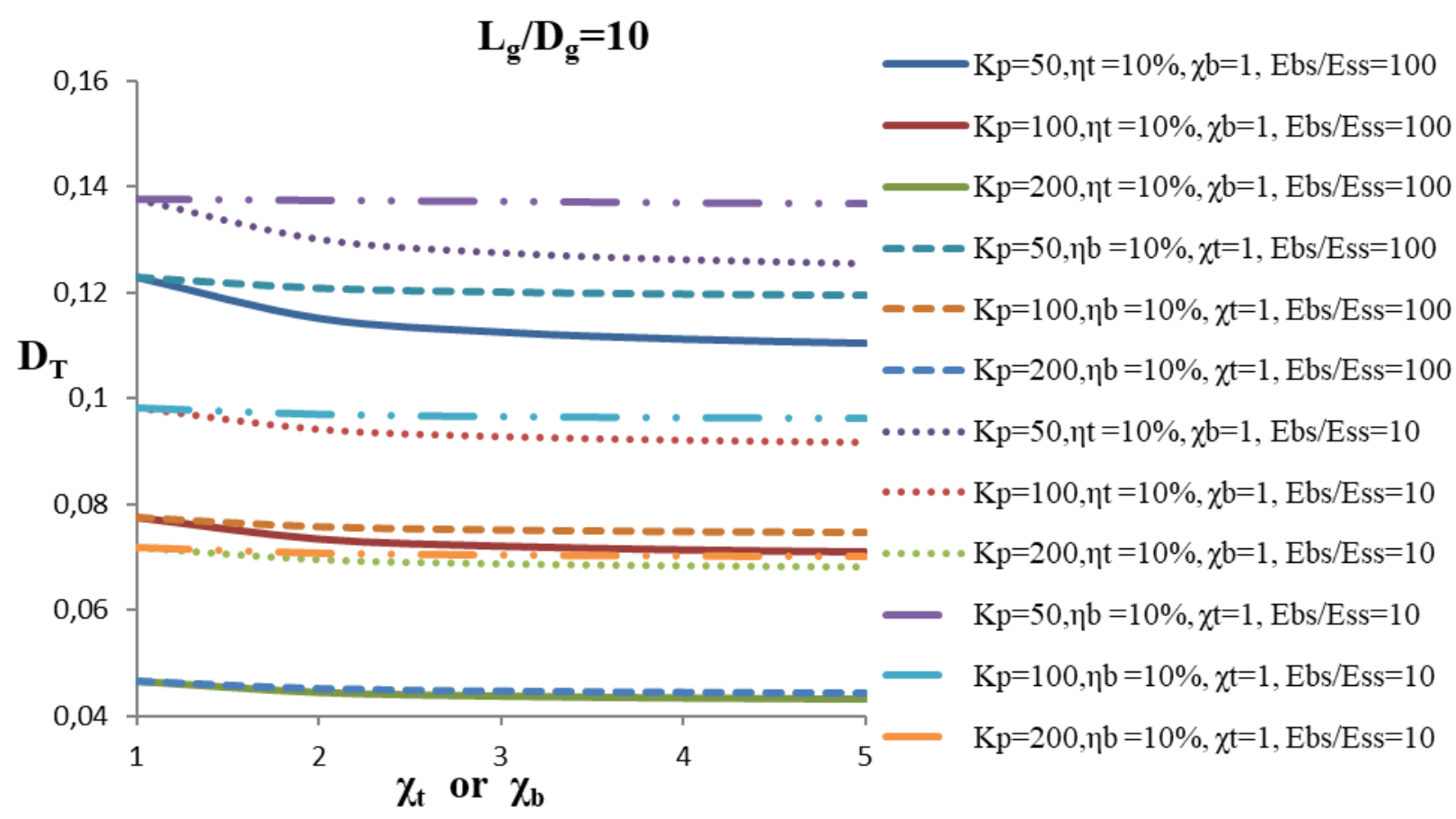

Figure 3: Variation of displacement affecting component for the top of $G P, D_{T}$, with strengthening factor for the top, $X_{\mathrm{t}}$, or strengthening factor for the bottom, $x_{b}$. Impact of the relative stiffness of GP, $\mathrm{K}_{\mathrm{p}}$; PLST of GP, $\eta_{\mathrm{t}}$; PLSB of GP, $\eta_{b}$; and relative stiffness of bearing stratum, $\mathrm{E}_{\mathrm{bs}} /$ $E_{s s}$, on a single partially strengthened $G P\left(L_{g} / D_{g}=10, \eta_{t}\right.$ or $\left.\eta_{b}=10 \%\right)$.

(vii)Strengthening factor for the top and bottom, $\chi_{t}$ and $\chi_{b}$ respectively.

\section{Results and Discussion}

The results for displacement effecting component for top of GP, $\mathrm{D}_{\mathrm{T}}$, are validated with the results obtained by Poulos and Mattes [20] in Table 1 for an unstrengthened single end-bearing GP, by selecting the values of both the parameters viz. strengthening factor for the top and strengthening factor for the bottom as unity.

The following paragraphs deal with the results and discussion of the ongoing analysis, by making the GP partially strengthened. Results, in general, are obtained for the following ranges of the above-defined parameters

$\mathrm{K}_{\mathrm{p}}=50-400, \eta_{\mathrm{t}}=10-40 \%, \eta_{\mathrm{b}}=10-40 \%, \chi_{\mathrm{b}}=1-5, \chi_{\mathrm{t}}=1-5$, $\mathrm{L}_{\mathrm{g}} / \mathrm{D}_{\mathrm{g}}=10-40, \mathrm{E}_{\mathrm{bs}} / \mathrm{E}_{\mathrm{ss}}=10-100$. The Poisson's ratio values for soil and bearing stratum are taken each equal to 0.5 in the following analysis.

Fig. 3 represents the variation of displacement affecting component for the top of $G P, D_{T}$, with strengthening factor for the top, $\chi_{t}$, or strengthening factor for the bottom, $\chi_{b}$. Both the PLST of GP and PLBT from the bottom of GP are taken as 10\%, as shown in Fig. 3.
As depicted in Fig. 3, in some curves, $\chi_{t}$ is taken as unity, implying that the strengthening effect is only applied at the bottom end. Hence, here the effect of variation of $\chi_{b}$ is depicted. Similarly, when $\chi_{b}$ is taken as one, it indicates that the strengthening effect is adopted at the top end of GP only, and hence its variation is shown. It can well be seen from the curves that when the strengthening effect is only provided at the bottom of GP, then the curve is almost linear, representing that this is not making considerable outcome on the parameter of displacement affecting component for the top of GP, $D_{T}$. But for the case of strengthening adopted for the bottom, the displacement affecting component for the top of $\mathrm{GP}, \mathrm{D}_{\mathrm{T}}$, decreases as the value strengthening factor for the top, $\chi_{t}$, increases. Besides this, it is visible that the value of displacement affecting component for the top of GP, $\mathrm{D}_{\mathrm{T}}$, decrease with an increase in relative stiffness of $\mathrm{GP}, \mathrm{K}_{\mathrm{p}}$ as well as relative stiffness of bearing stratum $\mathrm{E}_{\mathrm{bs}} / \mathrm{E}_{\mathrm{ss}}$, whatever may be the case, i.e., bottom strengthening or top strengthening. It may well be observed from the Fig. 3 that at $-\mathrm{L}_{\mathrm{g}} / \mathrm{D}_{\mathrm{g}}=10, \mathrm{E}_{\mathrm{bs}} /$ $E_{s s}=100, \chi_{t}=1, \eta_{t}=10 \%, K_{p}=50$, for $\chi_{b}=1,2,3,4$, and 5, the values of displacement affecting component for top of $\mathrm{GP}, \mathrm{D}_{\mathrm{T}}$ are, respectively, 0.1228, 0.1150, 0.1124, 0.1110, and 0.1103 , thus causing a decrease in percentage of $6.3,2.2$, 1.2 , and 0.6 with respect to $\chi_{\mathrm{b}}=1$; and at $\mathrm{L}_{\mathrm{g}} / \mathrm{D}_{\mathrm{g}}=10, \mathrm{E}_{\mathrm{bs}} / \mathrm{E}_{\mathrm{ss}}$ 


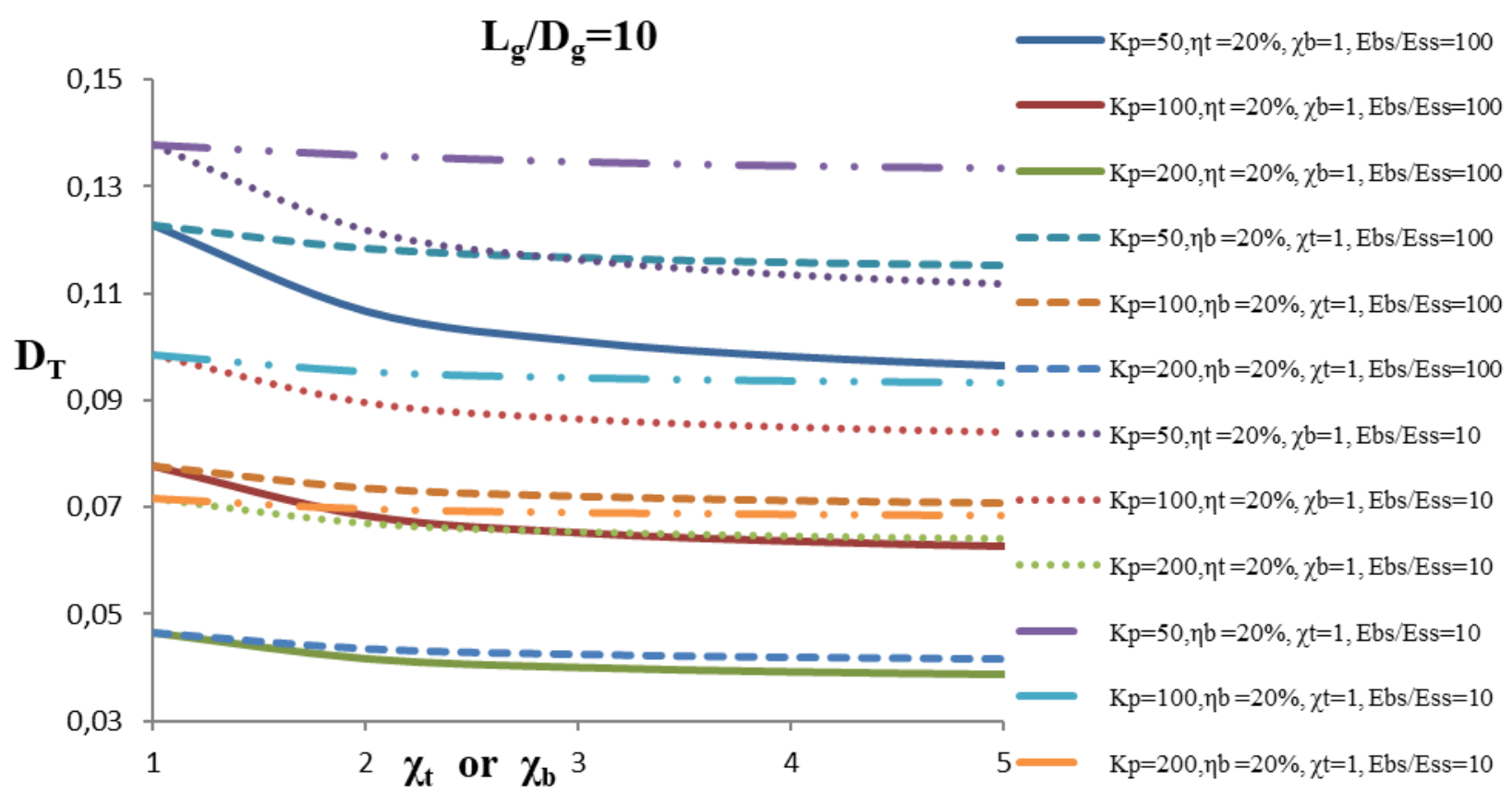

Figure 4: Variation of displacement affecting component for the top of GP, $D_{T}$, with strengthening factor for the top, $X_{t}$, or strengthening factor for the bottom, $X_{b}$. Impact of the relative stiffness of GP, $K_{p} ;$ PLST of GP, $\eta_{t}$; PLSB of GP, $\eta_{b}$; and relative stiffness of bearing stratum, $E_{b s} /$ $E_{s s}$, on a single partially strengthened $G P\left(L_{g} / D_{g}=10, \eta_{t}\right.$ or $\left.\eta_{b}=20 \%\right)$.

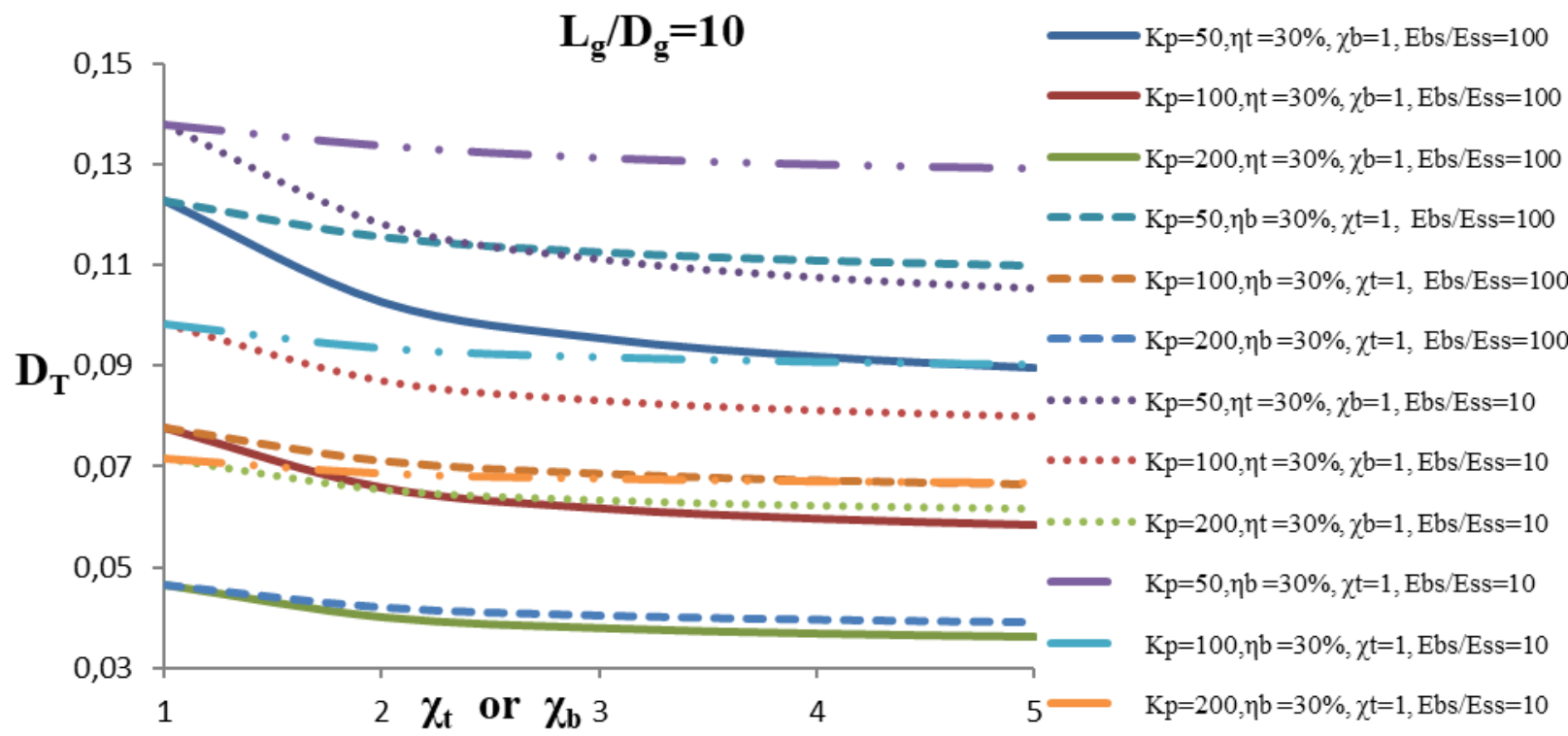

Figure 5: Variation of displacement affecting component for the top of GP, $D_{T}$, with strengthening factor for the top, $X_{t}$, or strengthening factor for the bottom, $X_{b}$. Impact of the relative stiffness of GP, $K_{p} ;$ PLST of GP, $\eta_{t}$; PLSB of GP, $\eta_{b}$; and relative stiffness of bearing stratum, $E_{b s} /$ $E_{s s}$, on a single partially strengthened $G P\left(L_{g} / D_{g}=10, \eta_{t}\right.$ or $\left.\eta_{b}=30 \%\right)$. 


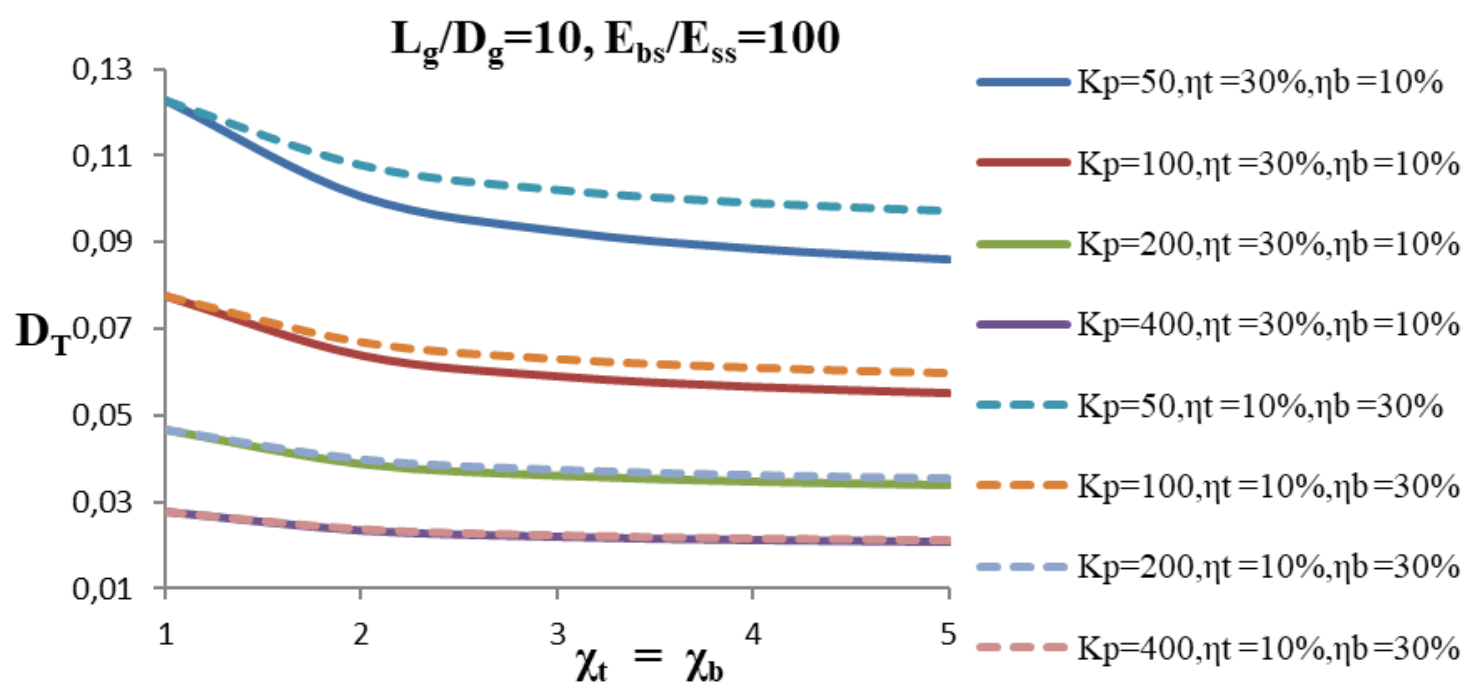

Figure 6: Variation of displacement affecting component for the top of GP, $D_{T}$, with strengthening factor for the top, $X_{t}$ or strengthening factor for the bottom, $X_{b}$ such that $X_{t}=X_{b}$. Impact of the relative stiffness of GP, $K_{p} ;$ PLST of GP, $\eta_{t}$; PLSB of GP, $\eta_{b}$; on a single partially strengthened $\mathrm{GP}\left(\mathrm{L}_{\mathrm{g}} / \mathrm{D}_{\mathrm{g}}=10, \mathrm{E}_{\mathrm{bs}} / \mathrm{E}_{\mathrm{ss}}=100\right)$.

$=100, \chi_{t}=1, \eta_{t}=10 \%, K_{p}=100$, for $\chi_{b}=1,2,3,4,5$, the values of displacement affecting component for top of GP, $\mathrm{D}_{\mathrm{T}}$ are, respectively, 0.0775, 0.0733, 0.0719, 0.0712, and 0.0708, thus causing a percentage decrease of 5.4, 1.9, 0.9 , and 0.5 with respect to $\chi_{\mathrm{b}}=1$.

Fig. 4 shows the variation of displacement affecting component for the top of GP, $\mathrm{D}_{\mathrm{T}}$, with strengthening factor for the top, $\chi_{\mathrm{t}}$, or strengthening factor for the bottom, $\chi_{b}$, as explained in Fig. 3. Both the PLST of GP and PLSB of GP are taken as 20\%, shown in Fig. 4. Thus, in contrast to Fig. 3 , the percentage length of strengthening is increased; rest effect is as it is. Hence, it can be observed from the curves that the values of displacement affecting component for the top of GP, $\mathrm{D}_{\mathrm{T}}$, are less than of the values in Fig. 3. For example, from observing the curves, it may well be noted that at, $\mathrm{L}_{\mathrm{g}} / \mathrm{D}_{\mathrm{g}}=10, \mathrm{E}_{\mathrm{bs}} / \mathrm{E}_{\mathrm{ss}}=100, \chi_{\mathrm{t}}=1, \eta_{\mathrm{t}}=20 \%, \mathrm{~K}_{\mathrm{p}}=100$, for $\chi_{b}=1,2,3,4$, and 5 , the values of displacement affecting component for top of $\mathrm{GP}, \mathrm{D}_{\mathrm{T}}$, are, respectively, 0.0775, $0.0684,0.0653,0.0637$, and 0.0627 , so causing a large percentage decrease of $11.7,4.5,2.4$, and 1.5 with respect to $\chi_{b}=1$.

Fig. 5 shows the variation of displacement affecting component for the top of $\mathrm{GP}, \mathrm{D}_{\mathrm{T}}$, with strengthening factor for the top, $\chi_{t}$, or strengthening factor for the bottom, $\chi_{b}$. Both the PLST of GP and the PLSB of GP are further increased to $30 \%$ in the Fig. 5 . By increasing the percentage length of strengthening, the values of displacement effecting component for the top of GP decrease more. The effect of the relative stiffness of the bearing stratum can well be seen from the Fig. 5. As shown in the Fig. 5, the value of displacement affecting component for top of GP, $D_{T}$, at $\mathrm{L}_{\mathrm{g}} / \mathrm{D}_{\mathrm{g}}=10, \mathrm{E}_{\mathrm{bs}} / \mathrm{E}_{\mathrm{ss}}=100, \chi_{\mathrm{t}}=1, \eta_{\mathrm{t}}=30 \%, \mathrm{~K}_{\mathrm{p}}=100, \chi_{\mathrm{t}}=2$ is 0.0869 , while with $E_{b s} / E_{s s}=10$ and rest parameters as it is, the value turns out to be 0.0638 , which decreases to $26.58 \%$.

Fig. 6represents the variation of displacementaffecting component for the top of GP, $\mathrm{D}_{\mathrm{T}}$, with strengthening factor for the top, $\chi_{t}$ or strengthening factor for the bottom, $\chi_{b}$, such that $\chi_{t}=\chi_{b}$. Due to simultaneous dual strengthening, the values of displacement affecting component for the top of GP, $D_{T}$ are less than to the values shown in earlier figures. Also, it is visible from the Fig. 6 that top strengthening causes more reduction in displacement affecting component for top of GP, $\mathrm{D}_{\mathrm{T}}$, as compared to the bottom strengthening. For example, it may be seen from the figure that at $-\mathrm{L}_{\mathrm{g}} / \mathrm{D}_{\mathrm{g}}=10, \mathrm{E}_{\mathrm{bs}} / \mathrm{E}_{\mathrm{ss}}=100, \eta_{\mathrm{t}}=30 \%$, $\eta_{b}=10 \%, \chi_{t}=\chi_{b}=3$ for $K_{p}=50,100,200$, and 400, the values of displacement affecting component for top of GP, $\mathrm{D}_{\mathrm{T}}$ are, respectively, 0.0925, 0.0590, 0.0359, and 0.0219, whereas at $-\mathrm{L}_{\mathrm{g}} / \mathrm{D}_{\mathrm{g}}=10, \mathrm{E}_{\mathrm{bs}} / \mathrm{E}_{\mathrm{ss}}=100, \eta_{\mathrm{t}}=10 \%, \eta_{\mathrm{b}}=30 \%, \chi_{\mathrm{t}}=\chi_{\mathrm{b}}=3$ for, $\mathrm{K}_{\mathrm{p}}=50,100,200$, and 400 , are respectively $0.1020,0.0629$, 0.0373 , and 0.0224 . Hence, it can be seen that the value of displacement affecting component for the top of GP decreases with the increase in the value of $\mathrm{K}_{\mathrm{p}}$.

Fig. 7 shows the variation of displacement affecting component for top of GP, $\mathrm{D}_{\mathrm{T}}$, with strengthening factor for the top, $\chi_{\mathrm{t}}$ or strengthening factor for the bottom, $\chi_{\mathrm{b}}$, such that $\chi_{t}=\chi_{b}$. In this Fig. 7, three factors vary namely relative stiffness of GP, $\mathrm{K}_{\mathrm{p}}$; PLST of GP- is increased further as in contrast to Fig. 6 , i.e., $\eta_{t}=20 \%$ or $40 \%$, similarly PLSB of 


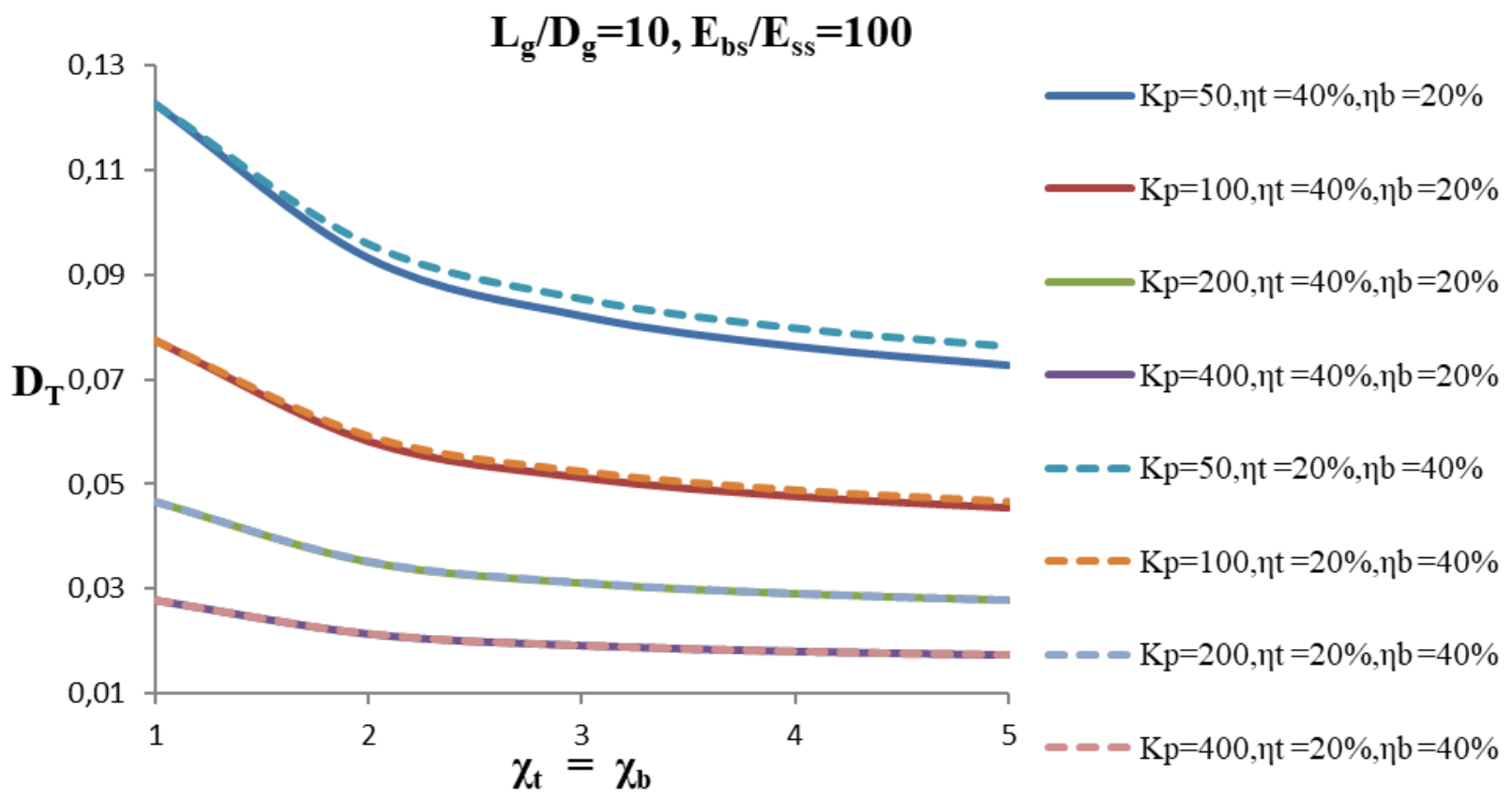

Figure 7: Variation of displacement affecting component for the top of GP, $D_{T}$, with strengthening factor for the top, $X_{t}$, or strengthening factor for the bottom, $\chi_{b}$ such that $\chi_{t}=\chi_{b}$. Impact of the relative stiffness of GP, $K_{p} ; P L S T$ of GP, $\eta_{t} ;$ PLSB of GP, $\eta_{b}$; on a single partially strengthened $G P\left(L_{g} / D_{g}=10, E_{b s} / E_{s s}=100\right)$.

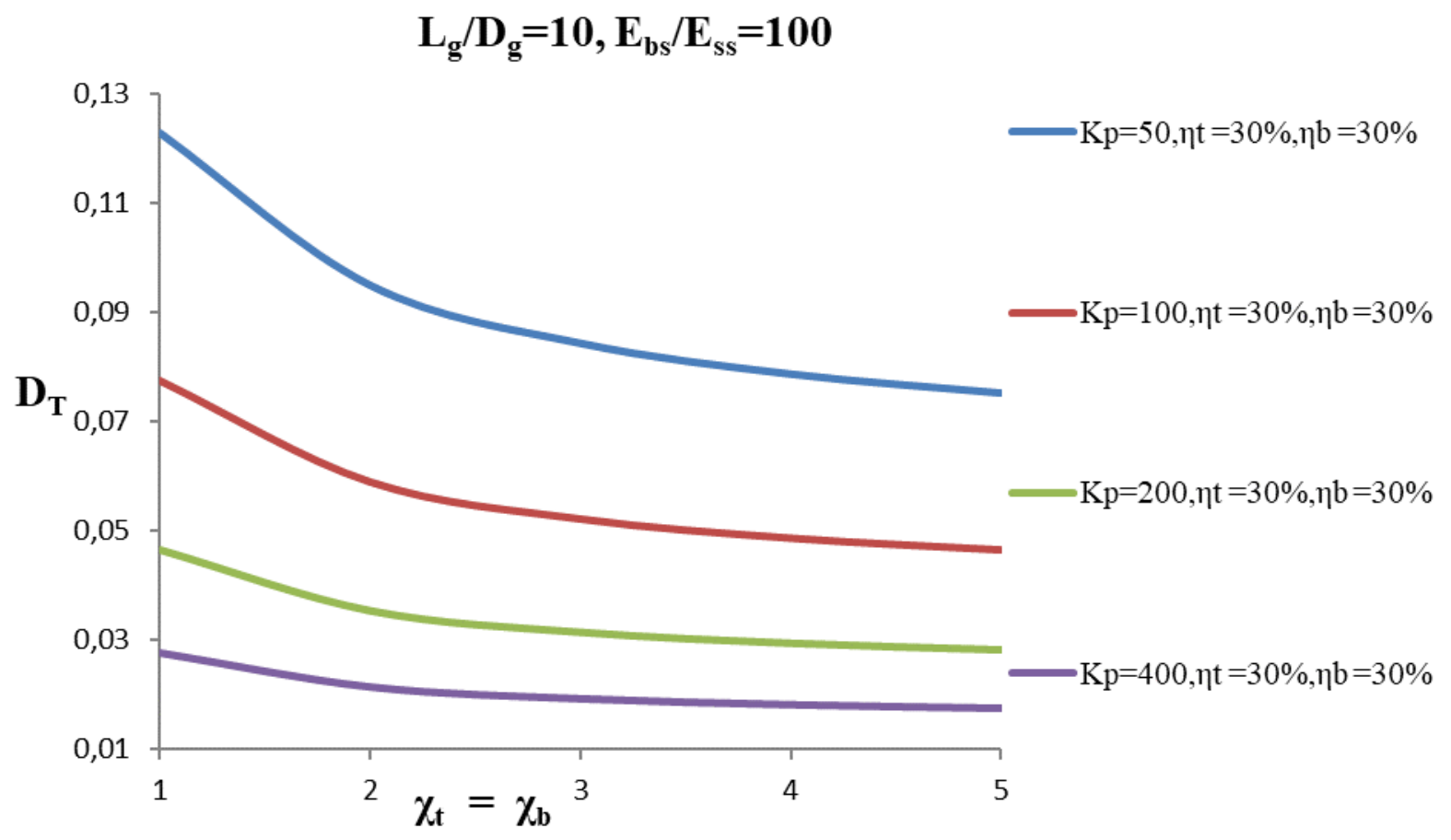

Figure 8: Variation of displacement affecting component for the top of GP, $D_{T}$, with strengthening factor for the top, $X_{t}$ or strengthening factor for the bottom, $X_{b}$, such that $X_{t}=X_{b}$. Impact of the relative stiffness of GP, $K_{p}$; PLST of GP, $\eta_{t}$; PLSB of GP, $\eta_{b}$; on a single partially strengthened $\mathrm{GP}\left(\mathrm{L}_{\mathrm{g}} / \mathrm{D}_{\mathrm{g}}=10, \mathrm{E}_{\mathrm{bs}} / \mathrm{E}_{\mathrm{ss}}=100\right)$ 


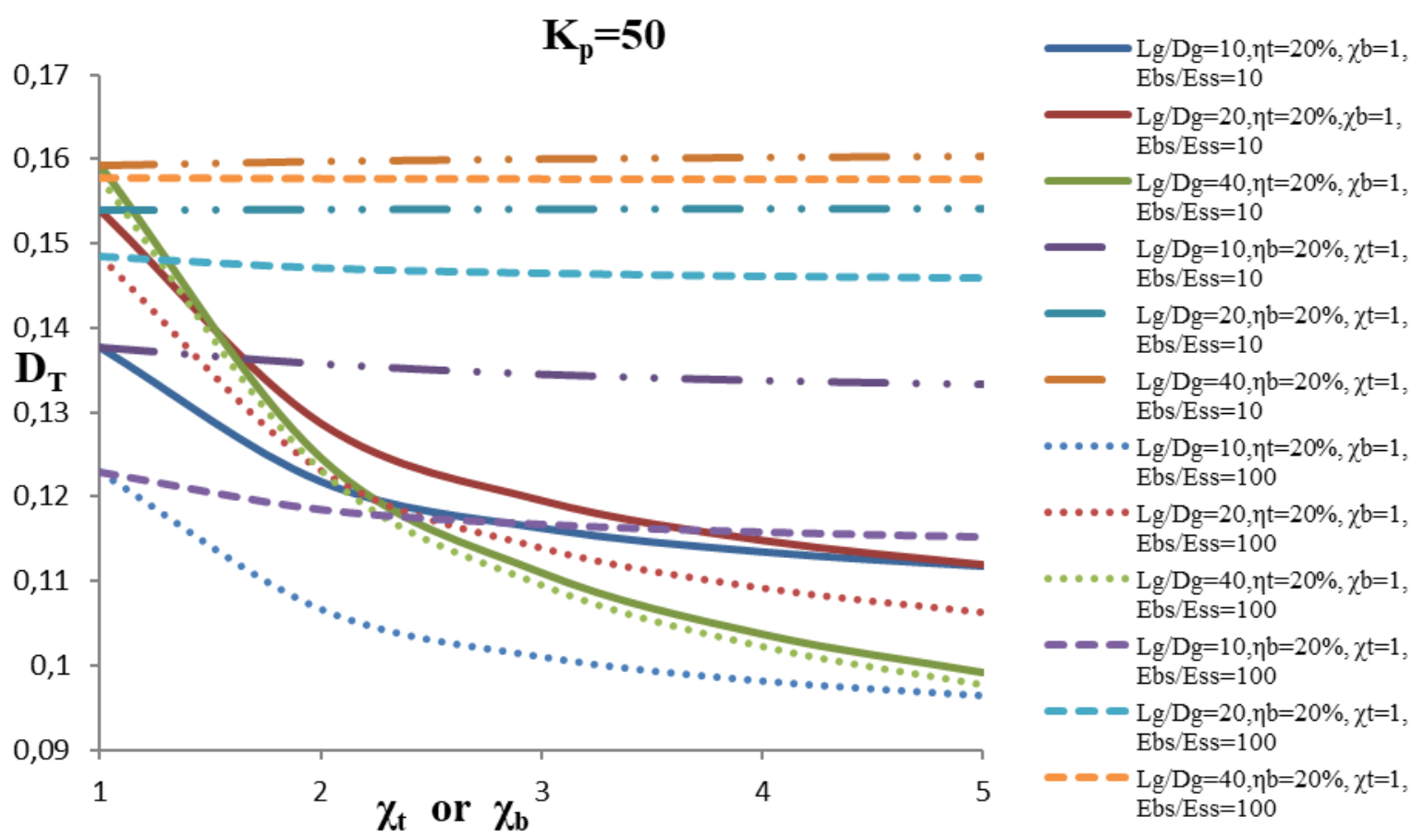

Figure 9: Variation of displacement affecting component for the top of $G P, D_{T}$, with strengthening factor for the top, $X_{t}$, or strengthening factor for the bottom, $X_{b}$. Impact of the relative length of $G P, L_{g} / D_{g} ; P L S T$ of $G P, \eta_{t}$; PLSB of GP, $\eta_{b}$; and relative stiffness of bearing stratum, $E_{b s} / E_{s s}$, on a single partially strengthened $G P\left(K_{p}=50, \eta_{t}=\eta_{b}=20 \%\right)$

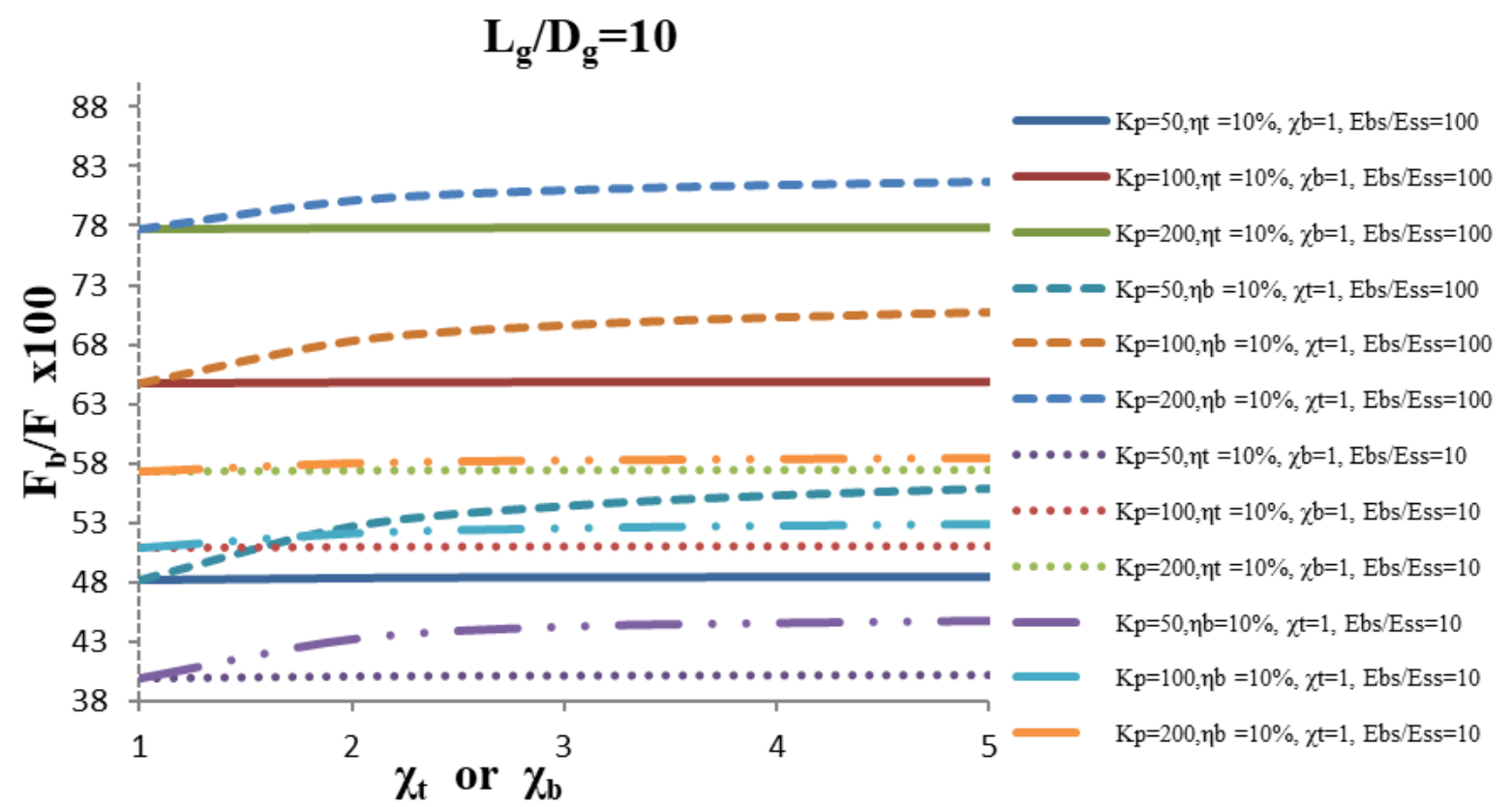

Fig. 10 Variation of PLTB of GP, $\left(F_{b} / F\right) \times 100$ with strengthening factor for the top, $X_{t}$, or strengthening factor for the bottom, $X_{b}$. Impact of the relative stiffness of GP, $K_{p}$, and relative stiffness of bearing stratum, $E_{b s} / E_{s s}$, on a single partially strengthened $G P\left(L_{g} / D_{g}=10, \eta_{t}\right.$ or $\left.\eta_{b}=10 \%\right)$ 


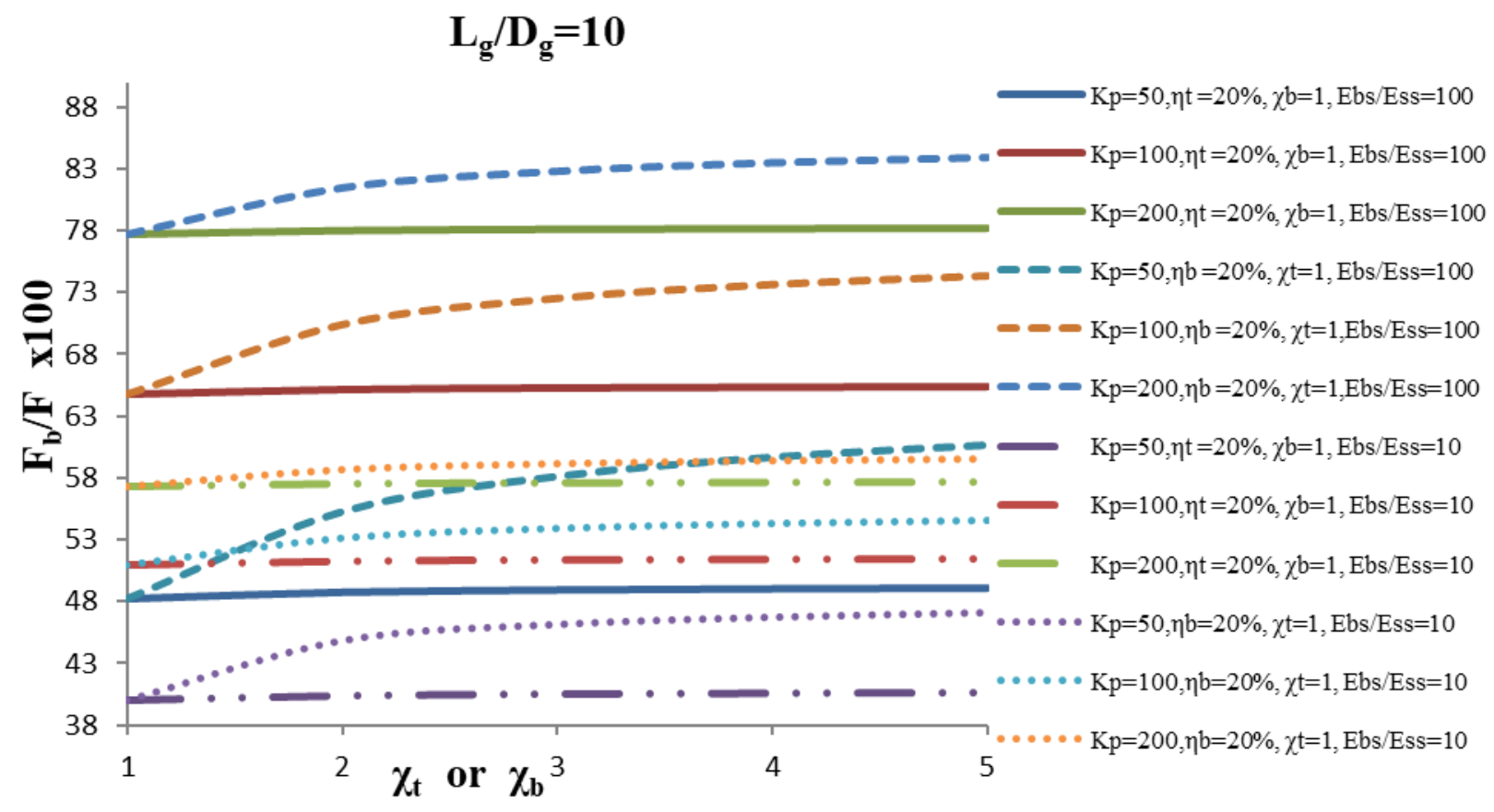

Figure 11: Variation of PLTB of GP, $\left(F_{b} / F\right) \times 100$ with strengthening factor for the top, $X_{t}$, or strengthening factor for the bottom, $X_{b}$. Impact of relative stiffness of $G P, K_{p}$, and relative stiffness of bearing stratum, $E_{b s} / E_{s s}$, on a single partially strengthened $G P\left(L_{g} / D_{g}=10, \eta_{t}\right.$ or $\left.\eta_{b}=20 \%\right)$.

GP also increased likewise, $\eta_{b}=40 \%$ and $20 \%$. The nature of the curves is same as in previous one, with a variation in values, i.e., in this case, the values are a little lower than the previous one because of higher percentage length of strengthening. For instance, at $-\mathrm{L}_{\mathrm{g}} / \mathrm{D}_{\mathrm{g}}=10, \mathrm{E}_{\mathrm{bs}} / \mathrm{E}_{\mathrm{ss}}=100$, $\eta_{\mathrm{t}}=40 \%, \eta_{\mathrm{b}}=20 \%, \chi_{\mathrm{t}}=\chi_{\mathrm{b}}=3$ for $\mathrm{K}_{\mathrm{p}}=50,100,200$, and 400, the values of displacement effecting component for top of $\mathrm{GP}, \mathrm{D}_{\mathrm{T}}$, are, respectively, 0.0821, 0.0513, 0.0310, and 0.0191, whereas at $-\mathrm{L}_{\mathrm{g}} / \mathrm{D}_{\mathrm{g}}=10, \mathrm{E}_{\mathrm{bs}} / \mathrm{E}_{\mathrm{ss}}=100, \eta_{\mathrm{t}}=20 \%, \eta_{\mathrm{b}}=40 \%$, $\chi_{\mathrm{t}}=\chi_{\mathrm{b}}=3$ for $\mathrm{K}_{\mathrm{p}}=50,100,200$, and 400, are, respectively, 0.0854, 0.0523, 0.0312, and 0.0190. However in Fig. 6, the values of displacement effecting component for top of GP, $D_{T}$, at $-L_{g} / D_{g}=10, E_{b s} / E_{s s}=100, \eta_{t}=10 \%, \eta_{b}=30 \%, \chi_{t}=\chi_{b}=3$ for $\mathrm{K}_{\mathrm{p}}=50,100,200$, and 400, are, respectively, 0.1020, 0.0629, 0.0373 , and 0.0224; hence it is clear that $\mathrm{D}_{\mathrm{T}}$ decreased with the increase in values of $\eta_{t}$ and $\eta_{b}$.

Fig. 8 shows the variation of displacement affecting component for top of GP, $\mathrm{D}_{\mathrm{T}}$, with strengthening factor for the top, $\chi_{\mathrm{t}}$, or strengthening factor for the bottom, $\chi_{b}$, such that $\chi_{t}=\chi_{b}$. The variation of three parameters namely relative stiffness of GP, $K_{p}$; PLST of GP, $\eta_{t}$; PLSB of GP, $\eta_{b}$; such that $\eta_{t}=\eta_{b}=30 \%$ is depicted here. At $L_{g} /$ $\mathrm{D}_{\mathrm{g}}=10, \mathrm{E}_{\mathrm{bs}} / \mathrm{E}_{\mathrm{ss}}=100, \eta_{\mathrm{t}}=30 \%, \eta_{\mathrm{b}}=30 \%, \chi_{\mathrm{t}}=\chi_{\mathrm{b}}=3$ for $\mathrm{K}_{\mathrm{p}}=50$, 100,200 , and 400, the values are, respectively, 0.0844 , 0.0522, 0.0314, and 0.0192, which are somewhat closer to the values shown in Fig. 7; at $-\mathrm{L}_{\mathrm{g}} / \mathrm{D}_{\mathrm{g}}=10, \mathrm{E}_{\mathrm{bs}} / \mathrm{E}_{\mathrm{ss}}=100, \eta_{\mathrm{t}}=$
$20 \%, \eta_{b}=40 \%, \chi_{t}=\chi_{b}=3$ for $K_{p}=50,100,200$, and 400, are, respectively, 0.0854, 0.0523, 0.0312, and 0.0190.

Fig. 9 shows the variation of displacement affecting component for the top of $\mathrm{GP}, \mathrm{D}_{\mathrm{T}}$, with strengthening factor for the top, $\chi_{\mathrm{t}}$, or strengthening factor for the bottom, $\chi_{b}$. This Fig. 9 depicts the variation of three different parameters: the relative length of GP, $\mathrm{L}_{\mathrm{g}} / \mathrm{D}_{\mathrm{g}}$, both the PLST of GP and the PLSB of GP are taken as 10\% and relative stiffness of bearing stratum, $\mathrm{E}_{\mathrm{bs}} / \mathrm{E}_{\mathrm{ss}}$. It has been found that for a longer pile, bearing stratum will be at a larger depth, and also the length of strengthening portion will be large; hence, the cumulative effect of both will reduce the displacement affecting component for the top of $\mathrm{GP}, \mathrm{D}_{\mathrm{T}}$, depending upon the length of the strengthening portion and depth of the bearing stratum as seen from the Fig. 9. Larger the depth of the bearing stratum, the lesser will be the reduction in $\mathrm{D}_{\mathrm{T}}$ and vice versa.

Fig.10 shows the variation of PLTB of GP, $\left(\mathrm{F}_{\mathrm{b}} / \mathrm{F}\right) \times 100$ with strengthening factor for the top, $\chi_{\mathrm{t}}$, or strengthening factor for the bottom, $\chi_{b}$. Both the percentage length of strengthening from the top of GP $\left(\eta_{t}\right)$ and the percentage length of strengthening from the bottom of GP $\left(\eta_{b}\right)$ are taken as $10 \%$ as shown in Fig. 10. It can well be seen from the Fig. 10 that when strengthening effect is only provided at the top of GP, then the curve is almost linear, showing that this is not producing a substantial effect 


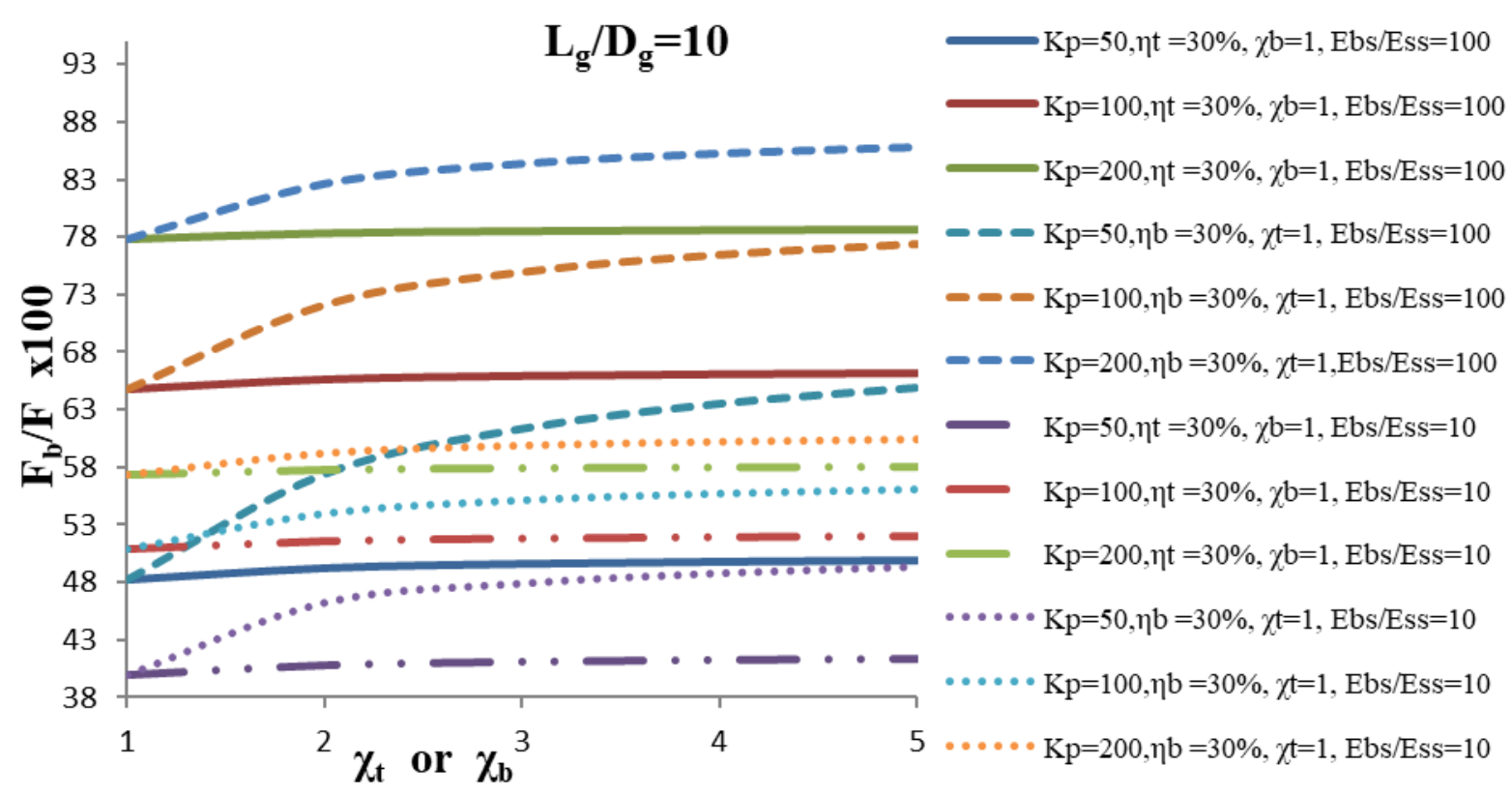

Figure 12: Variation of PLTB of GP, $\left(F_{b} / F\right) \times 100$ with strengthening factor for the top, $X_{t}$, or strengthening factor for the bottom, $X_{b}$. Impact of the relative stiffness of $\mathrm{GP}, \mathrm{K}_{\mathrm{p}}$, and relative stiffness of bearing stratum, $\mathrm{E}_{\mathrm{bs}} / \mathrm{E}_{\mathrm{ss}}$, on a single partially strengthened $\mathrm{GP}\left(\mathrm{L}_{\mathrm{g}} / \mathrm{D}_{\mathrm{g}}=10, \eta_{\mathrm{t}}\right.$ or $\left.\eta_{b}=30 \%\right)$.

on the parameter of PLTB of GP, $\left(F_{b} / F\right) \times 100$. But for the case of strengthening adopted for the bottom, the PLTB of GP, $\left(F_{b} / F\right) \times 100$ increases mainly till the strengthening factor for the bottom, $\chi_{b}$, becomes 3 ; thereafter, it becomes constant. Moreover, it can also be seen that the value of PLTB of GP, $\left(F_{b} / F\right) \times 100$ increases with an increase in relative stiffness of GP, $\mathrm{K}_{\mathrm{p}}$, and relative stiffness of bearing stratum $\mathrm{E}_{\mathrm{bs}} / \mathrm{E}_{\mathrm{ss}}$, whatever may be the case, i.e., bottom strengthening or top strengthening. But specifically for the case of bottom stiffening, the PLTB of GP, $\left(\mathrm{F}_{b} / \mathrm{F}\right) \times 100$ increases more for greater value of $\mathrm{E}_{\mathrm{bs}} / \mathrm{E}_{\mathrm{ss}}$. It may well be observed from the Fig. 10 that at $-\mathrm{L}_{\mathrm{g}} / \mathrm{D}_{\mathrm{g}}=10, \mathrm{E}_{\mathrm{bs}} / \mathrm{E}_{\mathrm{ss}}=100, \chi_{\mathrm{t}}$ $=1, \eta_{\mathrm{b}}=10 \%, \mathrm{~K}_{\mathrm{p}}=100$, for $\chi_{\mathrm{b}}=1,2,3$, and 4 , the value of PLTB of GP, $\left(\mathrm{F}_{\mathrm{b}} / \mathrm{F}\right) \times 100$ are, respectively, 64.74, 68.34, 69.65, and 70.34 , thereby causing an increase of $5.5,7.5$, and 8.6 with respect to $X_{b}=1$.

Fig. 11 shows the variation of PLTB of GP, $\left(\mathrm{F}_{\mathrm{b}} / \mathrm{F}\right) \times 100$ with strengthening factor for the top, $\chi_{t}$ or strengthening factor for the bottom, $\chi_{b}$. Both the percentage length of strengthening from the top of GP $\left(\eta_{1}\right)$ and the percentage length of strengthening from the bottom of GP $\left(\eta_{b}\right)$ are further increased in contrast to Fig. 10 and are taken as $20 \%$ in Fig. 11. Therefore, it can be observed from the Fig. 11 that the value of PLTB of GP, $\left(\mathrm{F}_{b} / \mathrm{F}\right) \times 100$ is on the higher side as compared to the values in Fig. 10. For instance, from observing the curves it may well be noted that at$\mathrm{L}_{\mathrm{g}} / \mathrm{D}_{\mathrm{g}}=10, \mathrm{E}_{\mathrm{bs}} / \mathrm{E}_{\mathrm{ss}}=100, \chi_{\mathrm{t}}=1, \eta_{\mathrm{b}}=20 \%, \mathrm{~K}_{\mathrm{p}}=100$, for $\chi_{\mathrm{b}}=1,2,3$, and 4, the value of PLTB of GP, $\left(\mathrm{F}_{\mathrm{b}} / \mathrm{F}\right) \times 100$ is, respectively, 64.74, 70.37, 72.49, and 73.61, thereby causing a large increase of 8.6, 11.9, and 13.7 with respect to $\chi_{b}=1$.

Fig. 12 shows the variation of PLTB of GP, $\left(F_{b} / F\right) \times 100$ with strengthening factor for the top, $\chi_{t}$ or strengthening factor for the bottom, $\chi_{b}$. Both the PLST of GP and the PLSB of GP are further increased to 30\% in the Fig. 12. By increasing the percentage length of strengthening, the values of PLTB of GP increase further. The effect of the relative stiffness of the bearing stratum can well be seen from the curve. As shown in the Fig. 12 the value of PLTB of GP, $\left(F_{b} / F\right) \times 100$ at $-L_{g} / D_{g}=10, E_{b s} / E_{s s}=100, \chi_{t}=1$, $\eta_{b}=30 \%, K_{p}=100, \chi_{b}=2$ is $72.11 \%$, while with $E_{b s} / E_{s s}=10$ and rest parameters as it is, the value turns out to be $53.99 \%$, thereby causing an increase of $33.56 \%$ with respect to $E_{b s} /$ $\mathrm{E}_{\mathrm{ss}}=10$.

Fig. 13 depicts the variation of PLTB of GP, $\left(\mathrm{F}_{\mathrm{b}} / \mathrm{F}\right) \times 100$ with strengthening factor for the top, $\chi_{\mathrm{t}}$, or strengthening factor for the bottom, $X_{b}$, such that $X_{t}=X_{b}$. The relative stiffness of GP, $K_{p}$, PLST, $\eta_{t}=10 \%$ or $30 \%$, PLSB of GP, $\eta_{b}=30 \%$ and $10 \%$ are the parameters which are considered here. Due to the simultaneous effect of the bottom and top strengthening, all the curves in Fig. 13 are curved. Owing to dual strengthening, the values of PLTB of GP, $\left(\mathrm{F}_{b} / \mathrm{F}\right)$ $\mathrm{x} 100$, are certainly higher than values in previous figures. Simultaneously, it can well be concluded from the Fig. 13 that bottom strengthening contributes more for PLTB of 


$$
\mathbf{L}_{\mathrm{g}} / \mathbf{D}_{\mathrm{g}}=\mathbf{1 0}, \mathbf{E}_{\mathrm{bs}} / \mathbf{E}_{\mathrm{ss}}=100
$$

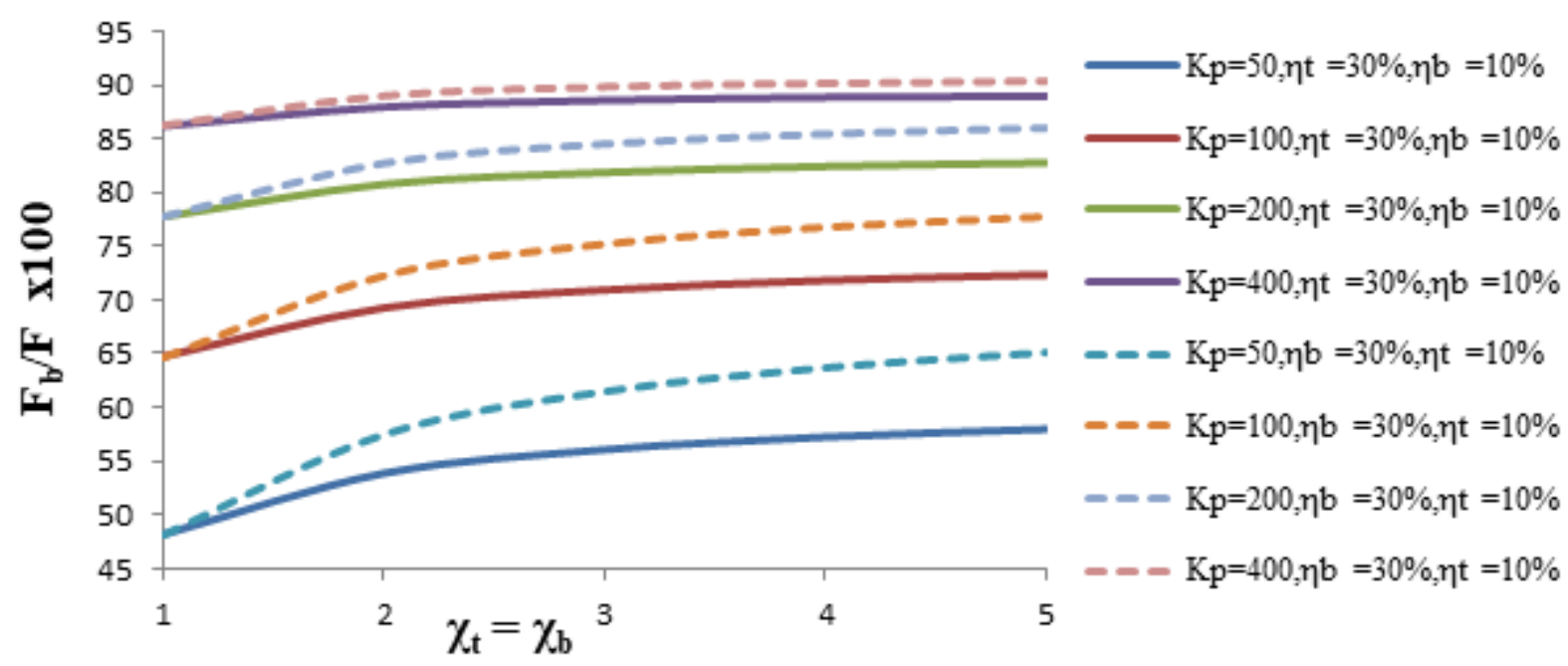

Figure 13: Variation of PLTB of GP, $\left(F_{b} / F\right) \times 100$ with strengthening factor for the top, $X_{t}$, or strengthening factor for the bottom, $X_{b}$, such that $X_{t}=$ $X_{b}$. Impact of the relative stiffness of GP, $K_{p}$; PLST of GP, $\eta_{t}$; PLSB of GP, $\eta_{b}$; on a single partially strengthened $G P\left(L_{g} / D_{g}=10, E_{b s} / E_{s s}=100\right)$.

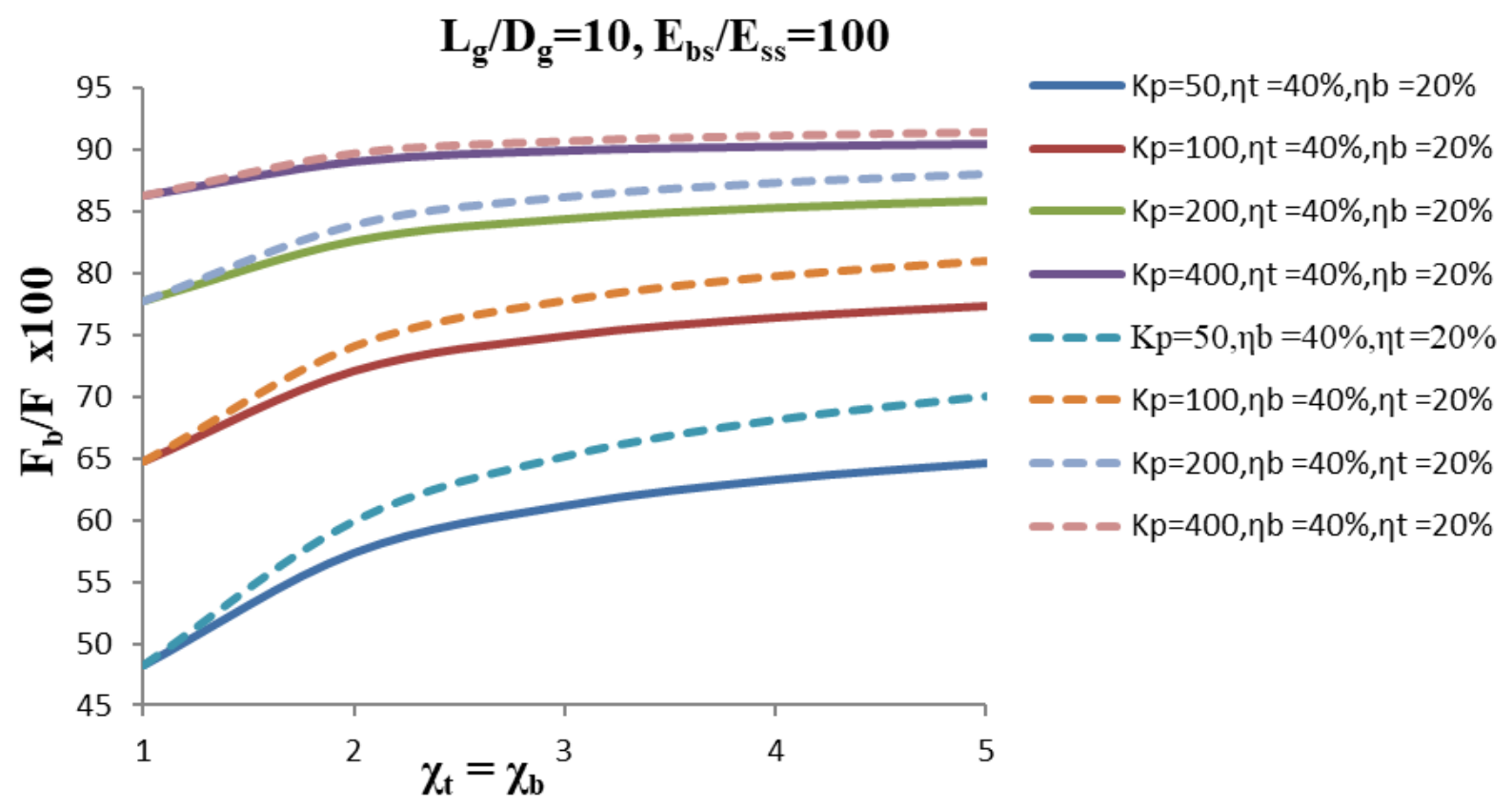

Figure 14: Variation of PLTB of GP, $\left(F_{b} / F\right) \times 100$ with strengthening factor for the top, $X_{t}$, or strengthening factor for the bottom, $X_{b}$, such that $X_{t}=$ $X_{b}$. Impact of the relative stiffness of GP, $K_{p}$; PLST of GP, $\eta_{t} ;$ PLSB of GP, $\eta_{b}$; on a single partially strengthened $G P\left(L_{g} / D_{g}=10, E_{b s} / E_{s s}=100\right)$.

$\mathrm{GP},\left(\mathrm{F}_{\mathrm{b}} / \mathrm{F}\right) \mathrm{x} 100$. For example it may be seen from the figure that at $-\mathrm{L}_{\mathrm{g}} / \mathrm{D}_{\mathrm{g}}=10, \mathrm{E}_{\mathrm{bs}} / \mathrm{E}_{\mathrm{ss}}=100, \eta_{\mathrm{t}}=30 \%, \eta_{\mathrm{b}}=10 \%, \chi_{\mathrm{t}}=\chi_{\mathrm{b}}=3$ for $\mathrm{K}_{\mathrm{p}}=50,100,200$, and 400, the values of PLTB of GP, $\left(\mathrm{F}_{\mathrm{b}} / \mathrm{F}\right)$ x100 are, respectively, $56.07,70.94,81.86$, and 88.57 , while that at $-\mathrm{L}_{\mathrm{g}} / \mathrm{D}_{\mathrm{g}}=10, \mathrm{E}_{\mathrm{bs}} / \mathrm{E}_{\mathrm{ss}}=100, \eta_{\mathrm{t}}=10 \%, \eta_{\mathrm{b}}=30 \%, \chi_{\mathrm{t}}=\chi_{\mathrm{b}}=3$ for $\mathrm{K}_{\mathrm{p}}=50,100,200$, and 400, the values are, respectively,
$61.58,75.15,84.48$, and 89.87. Thus, it can be seen that the percentage increase in the value of PLTB of GP decreases with the increase in the value of $\mathrm{K}_{\mathrm{p}}$.

Fig. 14 investigates the impact of relative stiffness of GP, $\mathrm{K}_{\mathrm{p}}$; PLST, $\eta_{\mathrm{t}}$; PLSB of GP, $\eta_{\mathrm{b}}$; on the variation of PLTB of $\mathrm{GP},\left(\mathrm{F}_{\mathrm{b}} / \mathrm{F}\right) \times 100$. The values of both the strengthening 


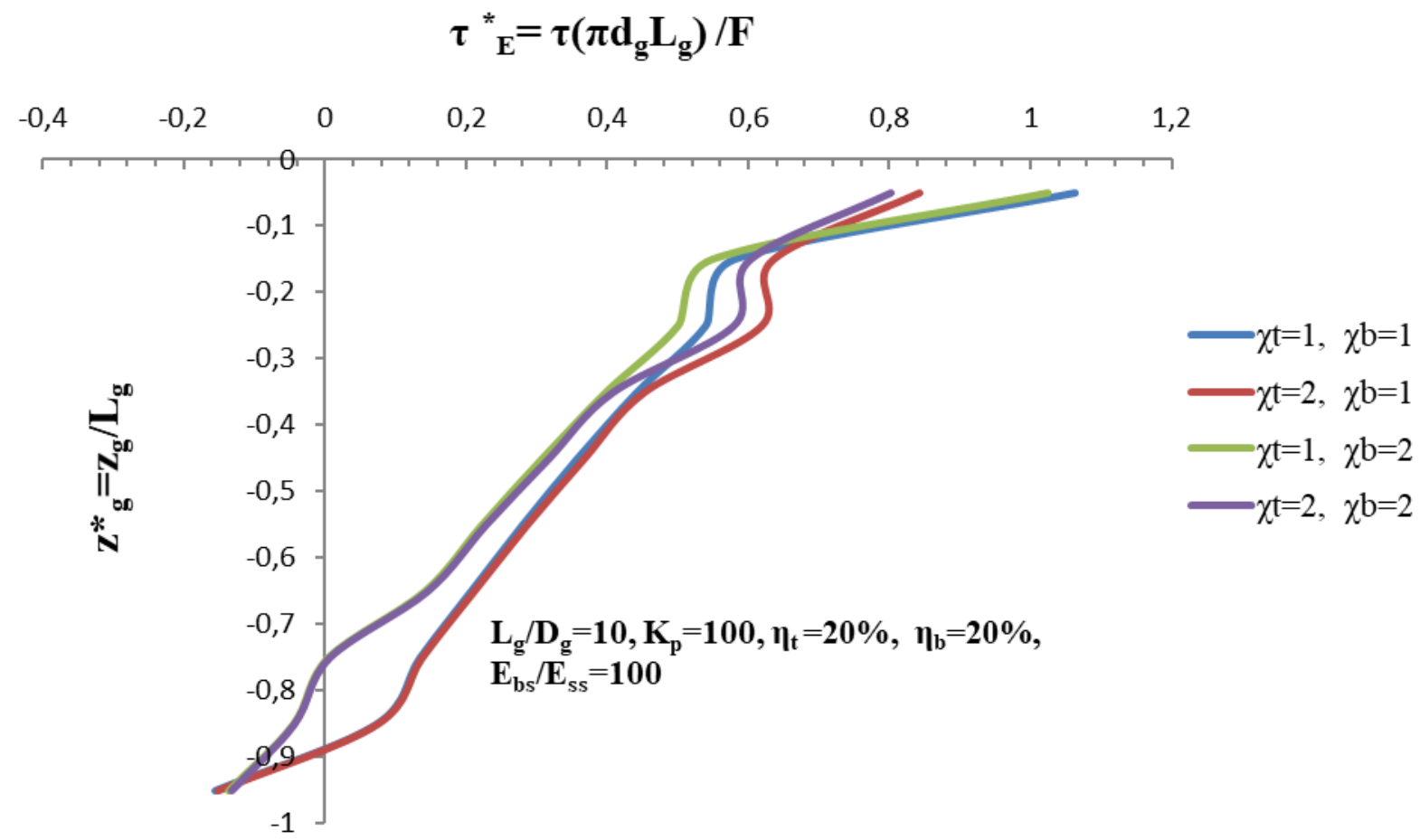

Figure 15: Variation of NSS, $\tau_{\mathrm{E}}^{\star}=\tau\left(\pi \mathrm{D}_{\mathrm{g}} \mathrm{L}_{\mathrm{g}}\right) / \mathrm{F}$ with normalized depth, $\mathrm{z}_{\mathrm{g}}^{*}=\mathrm{z}_{\mathrm{g}} / \mathrm{L}_{\mathrm{g}}$. Impact of strengthening factor for the top, $\mathrm{X}_{\mathrm{t}}$, or strengthening factor for bottom, $X_{b}$, on a single partially strengthened $G P\left(L_{g} / D_{g}=10, K_{p}=100, \eta_{t}=20 \%, \eta_{b}=20 \%, E_{b s} / E_{s s}=100\right)$.

$$
\tau{ }^{*}=\tau\left(\pi d_{g} L_{g}\right) / F
$$

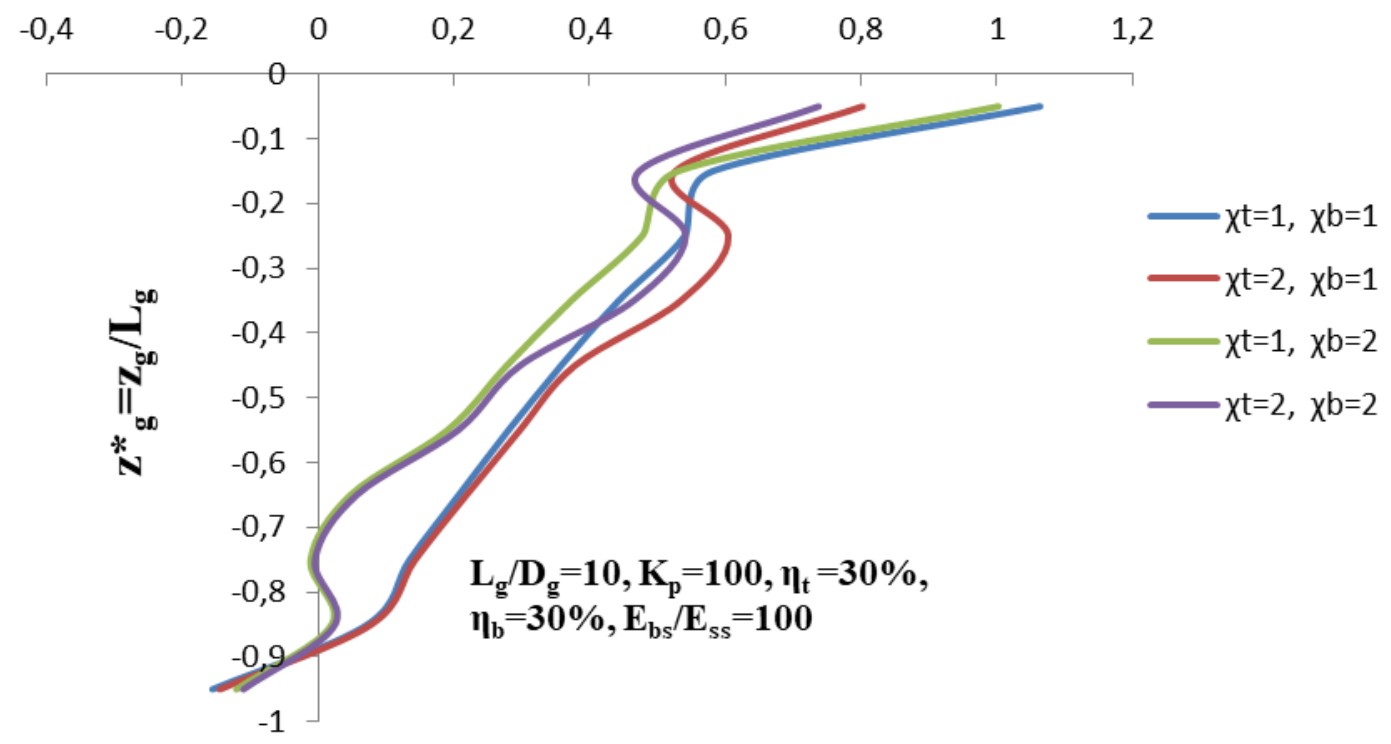

Figure 16: Variation of NSS, $\tau_{E}^{*}=\tau\left(\pi D_{g} L_{g}\right) / F$ with normalized depth, $z^{*}=z_{g} / L_{g}$. Impact of strengthening factor for the top, $X_{t}$, or strengthening factor for bottom, $X_{b}$, on a single partially strengthened $G P\left(L_{g} / D_{g}=10, K_{p}=100, \eta_{t}=30 \%, \eta_{b}=30 \%, E_{b s} / E_{s s}=100\right)$. 
factors are kept equal to each other. The PLST of GP, $\eta_{t}$, is taken higher, i.e., $40 \%$ and $20 \%$, and similarly PLSB of GP, $\eta_{b}$, varies as $20 \%$ and $40 \%$. The trends of the curves are same as earlier; with a difference in values, i.e., in this case the values are slightly higher because of higher percentage length of strengthening. As an example, it may well be established from the Fig. 14 that at $-\mathrm{L}_{\mathrm{g}} / \mathrm{D}_{\mathrm{g}}=10$, $E_{b s} / E_{s s}=100, \eta_{t}=40 \%, \eta_{b}=20 \%, X_{t}=X_{b}=3$ for $K_{p}=50,100$, 200 , and 400, the values of PLTB of GP, $\left(\mathrm{F}_{\mathrm{b}} / \mathrm{F}\right) \times 100$ are, respectively, $61.14,74.85,84.33$, and 89.85 , while that at$\mathrm{L}_{\mathrm{g}} / \mathrm{D}_{\mathrm{g}}=10, \mathrm{E}_{\mathrm{bs}} / \mathrm{E}_{\mathrm{ss}}=100, \eta_{\mathrm{t}}=20 \%, \eta_{\mathrm{b}}=40 \%, \chi_{\mathrm{t}}=\chi_{\mathrm{b}}=3$ for $\mathrm{K}_{\mathrm{p}}=50$, 100,200 , and 400 , the values are, respectively, 65.14, 77.78, 86.09, and 90.67. Thus, it may be concluded that if these data are compared with the data of Fig. 13, then at- $\mathrm{L}_{\mathrm{g}} /$ $\mathrm{D}_{\mathrm{g}}=10, \mathrm{E}_{\mathrm{bs}} / \mathrm{E}_{\mathrm{ss}}=100, \eta_{\mathrm{t}}=20 \%, \eta_{\mathrm{b}}=40 \%, \chi_{\mathrm{t}}=\chi_{\mathrm{b}}=3$ for $\mathrm{K}_{\mathrm{p}}=50$, 100,200 , and 400, there is an increase in the PLTB of GP, respectively, 5.7, 3.4, 1.9, and 0.8, by increasing top and bottom percent length of strengthening each by $10 \%$, i.e., at $-\mathrm{L}_{\mathrm{g}} / \mathrm{D}_{\mathrm{g}}=10, \mathrm{E}_{\mathrm{bs}} / \mathrm{E}_{\mathrm{ss}}=100, \eta_{\mathrm{t}}=10 \%, \eta_{\mathrm{b}}=30 \%, \chi_{\mathrm{t}}=\chi_{\mathrm{b}}=3$ for $\mathrm{K}_{\mathrm{p}}=$ 50, 100, 200, and 400.

Fig. 15 depicts NSS variation, $\tau_{\mathrm{E}}^{*}=\tau\left(\pi \mathrm{D}_{\mathrm{g}} \mathrm{L}_{\mathrm{g}}\right) / \mathrm{F}$ with normalized depth, $z^{\star}{ }_{g}=z_{g} / L_{g}$. The impact of the strengthening factor is shown. In Fig. 15, unstrengthened conditions are depicted, while in other, strengthening effect is presented with strengthening factor at top and bottom. It may well be seen from the Fig. 15 that the NSS is reduced at the top section of GP by introducing the strengthening, and the effect is maximized with the impact of strengthening introduced at both ends. The NSS is redistributed and shifted toward downside of the GP.

The variation of NSS, $\tau_{\mathrm{E}}^{*}=\tau\left(\pi \mathrm{D}_{\mathrm{g}} \mathrm{L}_{\mathrm{g}}\right) / \mathrm{F}$ with normalized depth, $z^{\star}{ }_{g}=z_{g} / L_{g}$ is shown in Fig. 16. The impact of strengthening factor is shown. Since the percent length of strengthening is increased by $10 \%$ on both sides, i.e., bottom and top, as compared to Fig. 15, the impact of this change is well visible from the curve that due to bottom strengthening, the NSS is reduced in the bottom strengthened portion of the GP. Rest effects are the same as described earlier.

\section{Conclusions}

Partially strengthened single end bearing GP, resting on a bearing stratum, strengthened at both ends is analyzed, using basic mirror image technique and basic integration scheme of Mindlin's equation. An entirely new matrix was developed incorporating the strengthening factor for the top of GP and strengthening factor for the bottom of GP.
1. It may be concluded that previous studies about the strengthening effect at the top of the GP are more effective in the reduction of displacements at the top, i.e., displacement effecting component for the top of GP as compared to the strengthening effect at the bottom of the GP. As observed from the study, the curve of displacement affecting component for the top of GP versus strengthening factor for either top or bottom reveals that the values of displacement affecting component for the top of GP are reduced more. The figure is a curved one with decreasing trends, in case of strengthening at the top, as in contrast to bottom strengthening, where the curve is almost linear.

2. In the case of dual strengthening, both the curves for displacement affecting component for the top of GP are curved one with decreasing trends.

3. It was concluded that as studied earlier, the strengthening at the top is not affecting much the PLTB of GP, but due to bottom strengthening, this value is affected considerably and found to increase. As observed in the analysis, it was noted that by providing strengthening at the top of GP, the PLTB of GP versus strengthening factor curve is almost linear. In contrast, the same figure is curved with increasing values for the case of bottom strengthening.

4. The PLTB of a strengthened GP is found to increase considerably in the range of strengthening factor for the bottom of GP, $\chi_{b}$, varying between 1 and 4. After the value of strengthening factor for the bottom of GP, $\chi_{b}$, exceeds 4 , the percentage load transferred to the base of the GP increases marginally only.

5. The study of NSS reveals that due to the dual effect of strengthening, the NSS is reduced at the top of the strengthened GP and is shifted in the downward direction along with the depth of the GP. Similarly, the NSS near the base end is also redistributed.

6. As for the future scope of the work, the study can be carried out on a group of strengthened end-bearing piles and, a pile with raft system.

\section{Funding: Not applicable}

Conflicts of interest/Competing interests: The authors declare that they have no known competing financial interests or personal relationships that could have appeared to influence the work reported in this article. 


\section{References}

[1] Madhav, M. R., Sharma, J. K., \& Chandra, S. (2006). Analysis and settlement of a non-homogeneous granular pile. Indian Geotechnical Journal, 36(3), 249-271.

[2] Mattes, N. S., \& Poulos, H. G. (1969). Settlement of single compressible pile. Journal of the Soil Mechanics and Foundations Division, 95(1), 189-207.

[3] Priebe, H. (1976). Estimating Settlements in a Gravel Column Consolidated Soil. Die Bautechnik 53, 160-163.

[4] Ambily, A. P., \& Gandhi, S. R. (2007). Behavior of stone columns based on experimental and FEM analysis. Journal of geotechnical and geoenvironmental engineering, 133(4), 405415.

[5] Black, J. A., Sivakumar, V., Madhav, M. R., \& Hamill, G. A. (2007). Reinforced stone columns in weak deposits: laboratory model study. Journal of Geotechnical and Geoenvironmental Engineering, 133(9), 1154-1161.

[6] Madhav, M. R., Sharma, J. K., \& Sivakumar, V. (2009). Settlement of and load distribution in a granular piled raft. Geomechanics and Engineering, 1(1), 97-112.

[7] Wang, G. (2009). Consolidation of soft clay foundations reinforced by stone columns under time-dependent loadings. Journal of geotechnical and geoenvironmental engineering, 135(12), 1922-1931.

[8] Najjar, S. S., Sadek, S., \&Maakaroun, T. (2010). Effect of sand columns on the undrained load response of soft clays. Journal of Geotechnical and Geoenvironmental Engineering, 136(9), 1263-1277.

[9] Black, J. A., Sivakumar, V., \& Bell, A. (2011).

The settlement performance of stone column foundations. Géotechnique, 61(11), 909-922.

[10] Yoo, C. (2010). Performance of geosynthetic-encased stone columns in embankment construction: numerical investigation. Journal of Geotechnical and Geoenvironmental Engineering, 136(8), 1148-1160.

[11] Shahu, J. T., \& Reddy, Y. R. (2011). Clayey soil reinforced with stone column group: model tests and analyses. Journal of Geotechnical and Geoenvironmental Engineering, 137(12), 1265-1274.

[12] Shahu, J. T., \& Reddy, Y. R. (2014). Estimating long-term settlement of floating stone column groups. Canadian geotechnical journal, 51(7), 770-781.

[13] Etezad, M., Hanna, A. M., \&Ayadat, T. (2015). Bearing capacity of a group of stone columns in soft soil. International Journal of Geomechanics, 15(2), 04014043.

[14] Hosseinpour, I., Almeida, M. S. S., \& Riccio, M. (2015). Full-scale load test and finite-element analysis of soft ground improved by geotextile-encased granular columns. Geosynthetics International, 22(6), 428-438.

[15] Hong, Y. S., Wu, C. S., \& Yu, Y. S. (2016). Model tests on geotextile-encased granular columns under 1-g and undrained conditions. Geotextiles and Geomembranes, 44(1), 13-27.

[16] Garg, V., \& Sharma, J. K. (2019). Analysis and settlement of partially stiffened single and group of two floating granular piles. Indian Geotechnical Journal, 49(2), 191-203.

[17] Madhav, M.R., Sharma, J.K., Garg, Vaibhaw, (2019). Stiffening effect on end bearing granular piles. A special issue Honouring
Dr Bengt. Fellenius, " Geotechnical Engineering Journal of The SEAGS and AGSSEA50, no. 3:32-40.

[18] Mindlin, R. D. (1936). Force at a point in the interior of a semiinfinite solid. physics, 7(5), 195-202.

[19] Mindlin, R. D. (1937). Stress system in a circular disk under radial forces, presented at the joint meeting of applied mechanics and hydraulic division of the ASME held at Cornell University, NY, pp. A115-118.

[20] Poulos, H. G., \& Mattes, N. S. (1969). The behaviour of axially loaded end-bearing piles. Geotechnique, 19(2), 285-300.

[21] Nav, M.A., Rahnavard, R., Noorzad, A. and Napolitano, R., (2020), June. Numerical evaluation of the behavior of ordinary and reinforced stone columns. In Structures (Vol. 25, pp. 481490). Elsevier. https://doi.org/10.1016/j.istruc.2020.03.021.

[22] Szypcio, Z., (2000). Bearing capacity of a single column. Studia Geotechnica et Mechanica, 22(3-4), pp.41-54.

[23] Sharma, J.K. and Gupta, P., (2018). Analysis and settlement evaluation of an end-bearing granular pile with non-linear deformation modulus. Studia Geotechnica et Mechanica, 40(3), pp.188-201. https://doi.org/10.2478/sgem-2018-0022. 